Linköping Studies in Science and Technology

Dissertation No. 2150

\title{
Investigating \\ Volume Change \\ and Ion Transport \\ in Conjugated \\ Polymers \\ Johannes Gladisch
}



Linköping Studies in Science and Technology. Dissertation No. 2150

Investigating Volume Change and Ion Transport in

Conjugated Polymers

Johannes Gladisch

1.0 UNKKODNESS

Department of Science and Technology, Laboratory of Organic Electronics

Linköping University, SE-581 83 Linköping, Sweden

Linköping 2021 
$(\mathrm{cc})$ EY-No 1 This work is licensed under a Creative Commons AttributionNonCommercial 4.0 International License.

https://creativecommons.org/licenses/by-nc/4.0/

Investigating Volume Change and Ion Transport in Conjugated Polymers

Johannes Gladisch

During the course of the research underlying this thesis, Johannes Gladisch was enrolled in Forum Scientium, a multidisciplinary graduate school at Linköping University, Sweden.

(C) 2021 Johannes Gladisch, unless otherwise noted

Printed in Sweden by LiU-tryck, 2021

ISSN: 0345-7524

ISBN: 978-91-7929-628-5 


\section{Abstract}

Volume changes are the foundation for a wide range of phenomena and applications, ranging from the movement of plants to valves and drug delivery devices. Therefore, it does not come as a surprise that controlled volume changes are an interesting topic of research. In this thesis, volume changes in polymers are the object of investigation. Polymers are a class of macromolecules that comprise repetitive units. Owing to the wide variety of such units, polymers can exhibit manifold properties, including but not limited to strong water attraction and electrical conductivity. The former is the defining property in polymer hydrogels while the latter is a core property of conducting polymers. Both the water attracting properties and conductivity are closely linked to transport events on a molecular level. In the case of hydrogels, it is predominantly water uptake, while in the case of conducting polymers it is a complex interplay between charges, ionic charge balancing entities and water. However, in either case the transport events lead to volume changes. Despite the similarities, the properties of the materials differ greatly. On the one hand volume changes in hydrogels are very large but hard to control. On the other hand, volume changes in conducting polymers are much smaller than in hydrogels, but the control is easier due to the electronic addressing.

$\mathrm{P}$ (gXTX) polymers combine a conducting polymer backbone with hydrogel sidechains. As described in publication 1, this combination of molecular entities was found to enabled unique properties of an electrically controllable giant volume change and concomitant solid-gel transition. In the second publication, the effect of the side chain lengths on the volume change properties of the polymers were explored. The knowledge acquired from these studies helped us to develop an electroactive filter based on p(gXTX) polymers which enabled electrochemical modulation of flow (publication 3). The aim of the fourth publication was to study the complex electronic-ionic transport processes and volume changes in a model conducting polymer, PEDOT:Tos.

The understanding of fundamental processes and properties of controllable volume changes may pave the way for advances in various applications, including electroactive meshes, actuators and drug delivery devices. 


\section{Populärvetenskaplig Sammfattning}

Volymförändringar är fundamentala i många fenomen och applikationer så som växters rörelser, ventiler och komponenter som kan leverera läkemedelssubstanser. Därför är det inte förvånande att kontroll av volymförändringar är ett viktigt forskningsområde. I denna avhandling så är volymförändringar i polymerer huvudfokuset. Polymerer är en klass av makromolekyler som består av repeterande enheter. Tack vare den stora variation som dessa enheter kommer i så kan polymerer uppvisa en mängs olika egenskaper, så som en stark bindningsförmåga till vatten samt elektrisk ledningsförmåga. Den förstnämnda egenskapen är den definierande egenskapen hos polymerbaserade hydrogeler medan den sistnämnda är den viktigaste egenskapen hos ledande polymerer. Både egenskapen att binda vatten och elektrisk ledningsförmågan är nära sammanlänkade till transportfenomen på molekylnivå. För hydrogeler så handlar detta främst om vattenupptagningsförmågan, medan för ledande polymerer så är det en komplex interaktion mellan laddningar, joniskt laddningsbalanserande enheter, och vatten. I båda fallen så leder dessa processer till volymförändringar. Trots de liknande utfallen så är materialens egenskaper mycket olika. Medan volymexpansion i hydrogeler har en stor effekt så är dessa processer svåra att kontrollera. Volymexpansion i ledande polymerer är istället mindre, men lättare att kontrollera då den kan styras elektroniskt.

Polymererna p(gXTX) kombinerar skelettstrukturen hos ledande polymerer med kemiska sidogrupper från hydrogeler. Så som beskrivs i publikation 1 så visade det sig att denna molekylära kombination ger unika egenskaper och en gigantisk elektriskt kontrollerbar volymförändring samt transformation mellan solid- och gel-form. I den andra publikationen så utforskades effekten hos sidogruppernas längd på volymexpansionen. Kunskapen som införskaffades under dessa undersökningar ledde till utvecklingen av ett elektroaktivt filter baserat på p(gXTX)-polymerer vilket möjliggjorde elektrokemisk modulation av flöden (publikation 3). Syftet med den fjärde publikationen var att studera den komplexa jon- och elektrontransporten och volymförändringar i en modell-polymer, PEDOT:Tos.

Genom att förstå de fundamentala processer och egenskaper hos kontrollerad volymförändring så kan nya genombrott ske inom olika applikationsområden så som elektroaktiva nätverk, aktuatorer, och läkemedelsleverans i kroppen. 


\section{Acknowledgement}

Proverbially no man is an island, this is very much true for a $\mathrm{PhD}$ thesis. This work would not have been possible without the contribution of many people, not just more than would reasonably fit on the cover, but so many that I might not even remember each one of them and you yourself might not even realize that you contributed somehow. Therefore, I would like to express my gratitude to:

My supervisors, Daniel, Eleni, Magnus and Valerio, for their guidance and support and giving me this opportunity.

Jesper \& Mats for their support with the Swedish abstract.

The e-plants team for being such a good team.

The colleagues at LOE and RISE for helping with good ideas and solutions for all the small and big issues in the lab and providing a nice work environment.

The lab crew for relentlessly fixing what we broke throughout our science endeavors.

All the other administrative team members for keeping everything running.

The numerous collaborators, internally and all over the world for fruitful collaborations. Vasilis for the great fun in our joint project. Sarbani for making the invisible visible. Najmeh for good collaboration.

My friends in Norrköping and all over the world for all the activities to have a good work life balance.

My friends and family in Germany.

Mina for making every day a great day and all her support. 
viii 


\section{List of Included Publications}

\section{Publication 1:}

Reversible Electronic Solid-Gel Switching of a Conjugated Polymer Johannes Gladisch, Eleni Stavrinidou, Sarbani Ghosh, Alexander Giovannitti, Maximilian Moser, Igor Zozoulenko, Iain McCulloch, Magnus Berggren

Advanced Science, 2020, 7, 1901144

Contributions: sample preparation, data acquisition, data

processing, data processing scripts, involved in writing

\section{Publication 2:}

Controlling Electrochemically Induced Volume Changes in Conjugated Polymers by Chemical Design: from Theory to Devices Maximilian Moser, Johannes Gladisch, Sarbani Ghosh, Tania Cecilia Hidalgo, James F. Ponder. Jr., Rajendar Sheelamanthula, Quentin Thiburce, Nicola Gasparini, Andrew Wadsworth, Alberto Salleo, Sahika Inal, Magnus Berggren, Igor Zozoulenko, Eleni Stavrinidou and Iain McCulloch

Advanced Functional Materials, 2021, NA, 2100723

Contributions: contributions to sample preparation, data acquisition, data processing, data processing scripts, involved in writing

\section{Publication 3:}

An electroactive filter with tuneable porosity Johannes Gladisch, Vasileios K Oikonomou, Maximilian Moser, Iain McCulloch, Magnus Berggren, Eleni Stavrinidou

Manuscript in preparation Contributions: sample preparation, data acquisition, setup design, data processing, data processing scripts, involved in writing

\section{Publication 4:}

Water Intake and Ion Exchange in PEDOT:Tos Film upon Cyclic Voltammetry: Experimental and Molecular Dynamics Investigation Najmeh Delavari. Johannes Gladisch, Ioannis Petsagkourakis, Mohsen Modarresi, Eleni Stavrinidou, Mathieu Linares, Igor Zozoulenko

Submitted to Macromolecules Contributions: acquired and processed the MD complementing experimental data, involved in writing 


\section{Related Work not Included in the Thesis}

Publication 5:

Side Chain Redistribution as a Strategy to Boost Organic Electrochemical Transistor Performance and Stability

Maximilian Moser, Tania Cecilia Hidalgo, Jokubas Surgailis, Johannes Gladisch, Sarbani Ghosh, Rajendar Sheelamanthula, Quentin Thiburce, Alexander Giovannitti, Alberto Salleo, Nicola Gasparini, Andrew Wadsworth, Igor Zozoulenko, Magnus Berggren, Eleni Stavrinidou, Sahika Inal, Iain McCulloch

Advanced Materials, 2020, 32, 2002748

\section{Publication 6:}

Toughening of a Soft Polar Polythiophene through Copolymerization with Hard Urethane Segments

Sepideh Zokaei, Renee Kroon, Johannes Gladisch, Bryan Paulsen, Wonil Sohn, Anna Hofmann, Gustav Persson, Arne Stamm, Per-Olof Syrén, Eva Olsson, Jonathan Rivnay, Eleni Stavrinidou, Anja Lund, Christian Müller

Advanced Science, 2021, 8, 2002778

\section{Publication 7:}

Cellulose-Conducting Polymer Aerogels for Efficient Solar Steam Generation

Shaobo Han, Tero-Petri Ruoko, Johannes Gladisch, Johan Erlandsson, Lars Wågberg, Xavier Crispin, Simone Fabiano

Advanced Sustainable Systems, 2020, 4, 2000004 


\section{Acronyms}

$\mathrm{BF}_{4}^{-}$

tetrafluoroborate

BMIM

1-butyl-3-methyl imidazolium

$\mathrm{CP}$

conjugated polymer

EG

ethylene glycol

EMI

1-ethyl-3-methylimidazolium

(e)QCM-D

LCST

NaDBS

OECT

OMIECs

P3MEEET

P3MEET

(electrochemical) quartz crystal microbalance with dissipation

lower critical solution temperature

sodium dodecylbenzenesulfonate

organic electrochemical transistor

organic mixed ionic-electronic conductors

poly(3-\{[2-(2-methoxyethoxy)ethoxy]ethyl\}-thiophene-2,5-diyl)

poly(3-[2-(2-methoxyethoxy)ethoxy]-thiophene2,5-diyl)

PC

propylene carbonate

PEDOT

poly(3,4-ethylenedioxythiophene)

PEG

poly(ethylene glycol)

PEO

poly(ethylene oxide)

$\mathrm{PF}_{6}{ }^{-}$

$\mathrm{P}$ (gXTX)

hexafluorophosphate

polythiophene with ethylene glycol sidechains of length $\mathrm{gX}$ and thiophene subunit repetitions TX

PNIPAAm poly(N-isopropylacrylamide)

poly(OEGMA)

poly(oligo ethylene glycol meth-acrylate)

Ppy

polypyrrole

PSS

polystyrene sulfonate

RGB

red green blue color model

S-PHE

sulfated poly( $\beta$-hydroxyether)

TEA

tetraethylammonium

TFSI

bis(trifluoromethanesulfonyl)imide

Tos tosylate

UCST

upper critical solution temperature 


\section{Table of Contents}

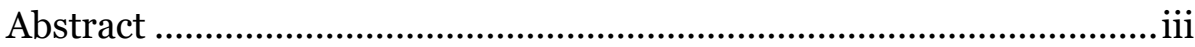

Populärvetenskaplig Sammfattning ..................................................... v

Acknowledgement..................................................................................... vii

List of Included Publications ................................................................... ix

Related Work not Included in the Thesis............................................... $\mathrm{x}$

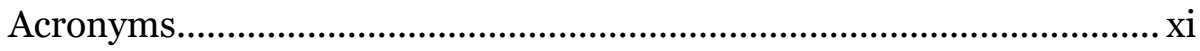

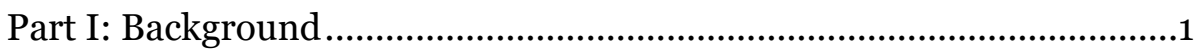

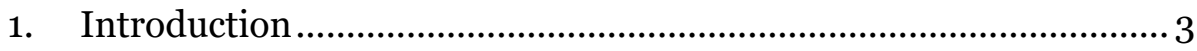

2. Aim of the Thesis .................................................................. 4

3. Materials .................................................................................... 5

3.1. Conjugated Polymers................................................................. 5

3.2. Hydrogels ............................................................................. 9

3.2.1. Fundamentals of Volume Changes in Hydrogels........ 9

3.2.2. Applications of Hydrogels ............................................ 11

3.3. Conjugated Polymers with Thiophene Backbone and Glycol Side Chains: p(gXTX)s........................................................................13

3.4. Induced Volume Changes in Different Polymer Classes....... 16

3.4.1. Volume Changes in Stimuli Responsive Hydrogels.. 16

3.4.1.1. pH Sensitive Hydrogels ............................................... 16

3.4.1.2. Temperature Sensitive Hydrogels .............................. 16

3.4.1.3. Temperature Sensitive Hydrogels with Ethylene Glycol Side Chains......................................................................................17

3.4.2. Volume Change in Conjugated Polymers.................. 18

4. Applications .................................................................................... 23

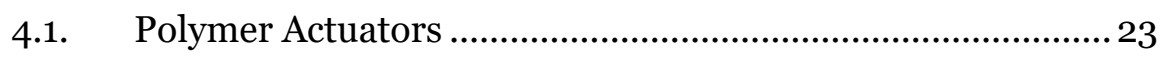

4.1.1. Actuator Applications ............................................... 23

4.1.1.1. Soft Robotics............................................................... 23

4.1.1.2. Different Actuator Architectures ................................ 24

4.1.1.2.1. 2-3 Layer Actuators .................................................. 24

4.1.1.2.2. Textile Actuators ...................................................... 25

4.2. Flow Control with Polymer Actuators ....................................28

4.2.1. Microfluidics ...............................................................28 
4.2.2. Separation Applications .............................................29

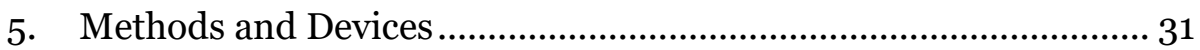

5.1. Quartz Crystal Microbalance.................................................. 31

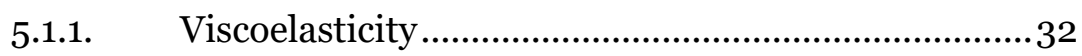

5.1.2. Limitations of the QCM Technique ........................... 32

5.2. Image Processing ..................................................................... 33

5.2.1. Computational Determination of Polymer Volume on Carbon Fibers ................................................................................. 33

5.2.2. Determination of Pore Sizes in Meshes...................... 34

5.3. 3D Printing............................................................................. 35

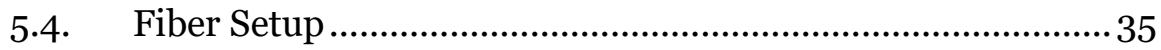

5.4.1. Deposition of Polymers on Carbon Fibers ................. 35

5.4.2. Micrograph Acquisition of Fibers ................................ 36

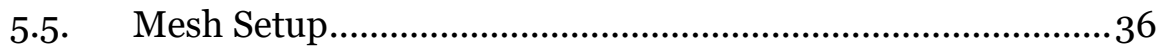

6. Summary and Outlook ........................................................................39

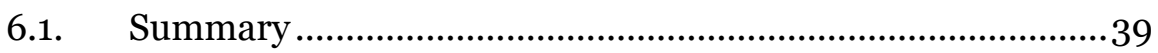

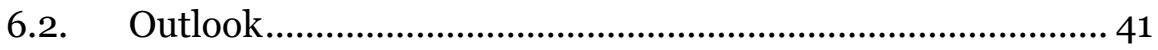

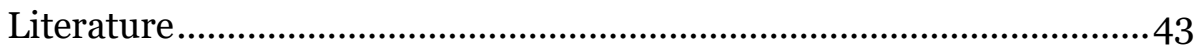

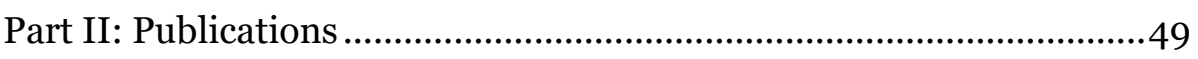


Part I: Background 


\section{Introduction}

During the history of mankind, materials science milestones repeatedly marked fundamental changes. Not for nothing historians named entire eras after materials science breakthroughs such as stone or bronze tools. Nowadays the pace of science might be too fast for new findings to define an era. However, the development and mass production of polymers also fundamentally changed everyday life. So much so, that even though we hardly notice, life as we know it would be impossible without polymers. The fact that polymers are omnipresent is related to the wide variety of polymers and corresponding wide variety of properties.

Conductivity has long been dismissed as a key property of polymers. Nonetheless, mostly driven by an interest into the production of dyes at that time, polyaniline, now known to be conductive, was already reported in $1826^{[1]}$. Owing to the predominant interest in dyes, those materials had many names, among others, names that persist such as emeraldine and aniline (a name for the indigo plant) ${ }^{[1]}$. Only in the 1970s investigations unveiled the conductive nature of certain polymers ${ }^{[1]}$. Those studies were awarded with a Nobel Prize in 2000 and sparked the field of organic electronics, on which now more than one thousand publications are published annually ${ }^{[1,2]}$. Nowadays many applications of organic electronics have been developed, including but not limited to antistatic coatings, electrochemical transistors, energy storage devices, actuators and drug delivery devices. Another application are electrochromic devices, which close the loop to the first investigations on polyaniline which already back then was found to have different colors under different circumstances ${ }^{[1]}$.

The ability to incorporate vast amounts of water into the polymer matrix makes hydrogels another type of polymers that aroused large research and commercial interest. On the one hand, natural hydrogels such as gelatin and alginate have been in use for hundreds if not thousands of years. On the other hand, just in the 1960 s new materials have been described by typical hydrogel properties [3]. Nowadays hydrogels can be found in ordinary commercial products like diapers.

Despite the plethora of exciting materials that have already been discovered new materials are developed all the time enabling improvements of given applications or completely new applications. Polymers that combine conjugated polymer backbones with sidechains of hydrogel character, potentially combine the best of both worlds, electrical properties like in the conjugated polymer backbone with volume changes of hydrogels like in the sidechains. The focus of this thesis is to explore the promise of such materials and gain better understanding of them. 


\section{Aim of the Thesis}

Conjugated polymers are a class of materials that has gained great attention in the recent past and has been thoroughly studied in many ways.

Nonetheless, new chemical designs enable enhancements of the material properties. Moreover, the improvements in measurement techniques or other fields such as molecular dynamics simulations still lead to better understanding of seemingly well studied materials.

In this thesis, the focus was on the quantification of the volume changes and the underlying molecular mechanism of the volume change in conjugated polymers.

In publications 1 to 3 , polythiophenes with ethylene glycol sidechains ( $\mathrm{p}(\mathrm{gXTX}) \mathrm{s})$, a rather recently developed group of polymers, were investigated. The combination of a conjugated polymer backbone with sidechains of hydrogel nature holds great promise for remarkable material properties. In fact, those polymers happen to not just exhibit remarkable ionic-electronic conductive properties but also exceptional electrochemically controllable volume changes.

The latter was thoroughly investigated in publication 1 for the first time. On top of that, the impact of the side chains on the volume change capabilities were examined in publication 2 . Finally, in the $3^{\text {rd }}$ publication the giant volume change capabilities of such polymers came into play for an electroactive mesh with controllable pore size and the ability to control flow.

Volume changes in conjugated polymers are closely linked to the movement of charged species. That is the case for polythiophenes with ethylene glycol sidechains, but also for well-established conjugated polymers such as PEDOT. In publication 4, the molecular processes occurring in PEDOT:tosylate during cyclic voltammetry were investigated. In this study my experimental work was complementing molecular dynamics simulations, also referred to as computational microscopy, which was used to gain a deeper insight into the processes occurring during cyclic voltammetry on a molecular level.

The introductory part is structured around the scope of the thesis. At first, the relevant materials, conjugated polymers and hydrogels are introduced. Then the volume change in the respective materials is described, followed by applications of volume changes. Lastly details on the applied techniques and setups is provided. 


\section{Materials}

\subsection{Conjugated Polymers}

Polymers are macromolecules that are comprised of a large number of one or multiple different repetitive units. Their diversity and wide range of properties are fundamental for many amenities of modern life. In historical terms, for the most part, the focus for the development of polymers was on their mechanical properties and processability. The latter is causative to why many polymer-based products in every-day contexts are often referred to as plastics. The wide interest in mechanical properties and processability are also reflected in the most common use case of polymers, which is in packaging [4]. The most common polymers these days are polyethylene and polypropylene ${ }^{[4]}$. Both polymers have in common, that they have backbones made of carbon atoms with $\sigma$ bonds between them. In such bonds, the electron clouds, i.e., the maximum spatial likelihood of the electrons or probability distribution, overlap and interact with the respective other atom nucleus (Figure 1). Note that while the bonds in the backbone are important, they are only one of the factors defining the polymer properties. (The bonds are of utmost importance for polymer conductivity though.)

a)

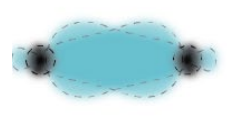

b)

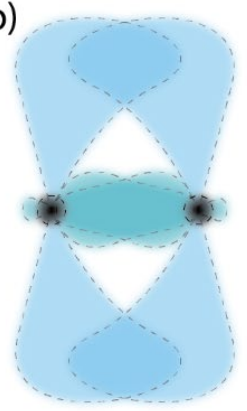

c)

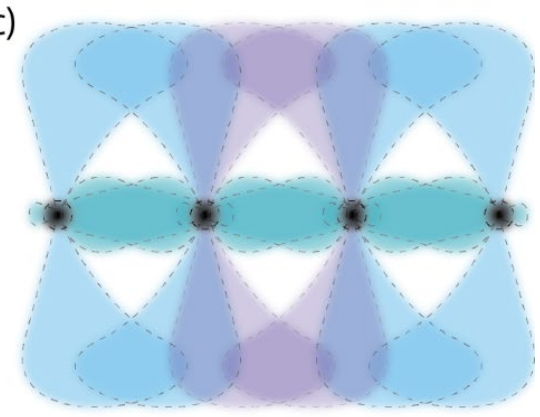

Figure 1 overlap of the electron clouds in a) $\sigma$ bindings, $b$ ) $\pi$ bindings between two atoms and c) in the case of alternating double bonds

In parallel to the development of polymers with mechanical properties in mind, chemists were vigorously producing dyes. In fact, polyaniline predates other polymers by decades, marking the beginning of the commercial polymer industry [5]. Even though, polyaniline is today a commonly known conducting polymer, its conductivity was long overlooked, and generally conductivity has long been considered as none of those 
properties polymers exhibit. Only in the 1960 s conductivity in polymers was reported ${ }^{[1]}$.

The unique characteristic, that distinguishes conducting polymers from non-conducting ones, are alternations of $\pi$-bonds and single bonds. In $\pi$-bonds, additional electron clouds interact with the respective neighboring nucleus, apart from the $\sigma$ interaction (Figure 1). However, the interaction between the electrons in that case is not as strong as in $\sigma$-bonds. In a situation of alternating $\pi$-bonds, so called conjugation, the interaction between the electron clouds involved in the $\pi$-binding, might occur either way with the neighboring nuclei. This uncertainty enables delocalization, i.e., movement, of charge carriers over the entire length of the conjugated system and is ultimately the key to the conductivity of polymers. Due to the underlying phenomena, such conducting polymers are also referred to as conjugated polymers.

Considering a bulk polymer, the limiting factor for charge transport is not the transport in a distinct polymer chain, but between polymer chains. That is because the length of a polymer chain is limited. On the one hand, inter chain charge transport can happen by thermally activated hops. The likelihood of the occurrence of such hops is rather low but increases with the number of charge carriers and multiplicity of energy levels. On the other hand, and much more favorable, are inter chain charge transfers through $\pi-\pi$-overlap when individual chains are $\pi-\pi-$ stacked ${ }^{6]}$. This $\pi-\pi$-stacking is typically associated with a higher order in the polymer bulk, i.e., crystallinity.

Like for classic semiconductors, there are $\mathrm{p}$ - and n- type conjugated polymers. In n-type materials, the charge carriers are excess electrons, while in p-type materials the charges are carried through positions of absent electrons, called holes. Currently p-type conjugated polymers are more common as they tend to be more stable at ambient conditions than ntype materials ${ }^{[7]}$.

Similar to semiconductors, the conductivity in conjugated polymers can be improved by increasing the charge carrier density through doping [8]. In conjugated polymers, it is distinguished between chemical and electrochemical doping ${ }^{[8]}$.

In the case of chemical doping, chemical compounds are introducing holes or electrons respectively. For p-type materials, the holes can be stabilized by negatively charged dopants. In PEDOT:Tos for example tosylate- acts as dopant to stabilize holes in the conjugated polymer backbone of PEDOT.

In electrochemical doping, a charge carrier (additional electron or hole) gets injected upon application of a potential to the polymer ${ }^{[9]}$. Following 
this process, mobile counter ions are moving in/out of the polymer matrix for charge compensation [9].

The movement of charged species can also lead to volume changes (see section 3.4 Induced Volume Changes in Different Polymer Classes) [6].

The described roles of charged species show how ionic and electronic charge transport are tied together in conjugated polymers. Given the importance of the movement of charged species in conjugated polymers, it seems natural that many $\pi$ conjugated polymers also exhibit ionic conductivity ${ }^{[6]}$. In fact, ionic transport is key for a wide range of applications including but not limited to familiar laboratory of organic electronics research subjects like energy storage devices, organic electrochemical transistors and ion pumps ${ }^{[6]}$. Materials that exhibit both ionic and electronic conductivity are called organic mixed ionic electronic conductors, in short OMIECs ${ }^{[6]}$. In OMIECs ionic and electronic transport are linked together by ionic-electronic coupling [6].

Paulsen et al. suggested a classification of OMIECs materials in 6 groups based on the one hand on dopant mobility and on the other hand on the OMIEC systems structural complexity (Figure 2) ${ }^{[6]}$. Where in the former case it is distinguished between the presence of generally immobilized ions and generally mobile ions and in the latter case it is differentiated between heterogeneous blends, heterogeneous block co-polymers and homogenous single-component systems ${ }^{[6]}$.

Group 1 polymers, like PEDOT:PSS comprise blends of a conjugated polymer (PEDOT) and an immobile polymeric dopant (PSS) which are arranged in heterogeneous fashion, as well as mobile counter ions ${ }^{[6]}$. Polymers of group 2 consist of conjugated polymers and polymer-electrolyte blends, e.g., hydrophilic polymers like polyethylene oxide, that retain the electrolyte with the mobile ions. That is to say, in group 1 the defining dopant is fixed, while in group 2 the defining dopant is mobile.

In group 3 polymers, the components of group 1 polymers are united in block-co-polymers. Likewise, group 4 polymers are block-co-polymers of group 2 components. Group 5 and 6 polymers combine the functional components in group 1 and 2 polymers respectively, in single homo polymeric molecules with conjugated polymer backbones and corresponding side chains. More precisely in group 5 polymers, e.g., PEDOT-S (PEDOT with a sidechain with a sulfonate group at the end), doping functional units are incorporated into the polymer sidechains. In group 6 materials comprise a $\pi$ conjugated polymer backbone, e.g. polythiophene, that is electronically conductive, and sidechains that are able to retain the electrolyte, such as ethylene glycol ${ }^{[6]}$. Hereby both positively and negatively charged species are mobile within the retained electrolyte and 
consequently the polymer matrix. Group 6 polymers are of particular interest for this thesis as polythiophenes with oligo ethylene glycol sidechains belong to this group ${ }^{[6]}$.

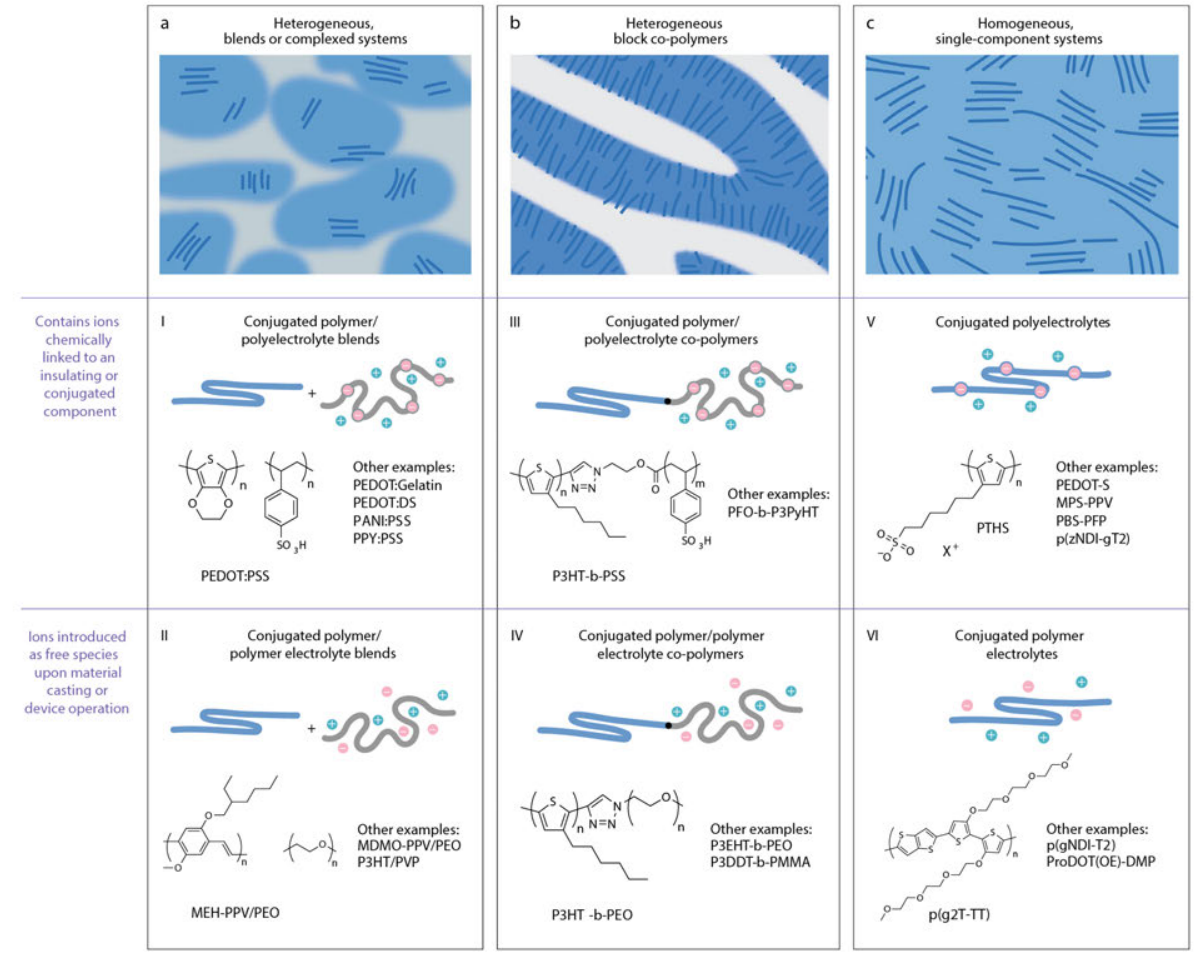

Figure 2 Overview of the OMIECs classes I-VI with columns a) heterogeneous blends or complexed systems, b) heterogeneous block co-polymers and c) homogeneous single-component systems, as well as row 1, polymers with linked ions and 2 polymers with free ions (reproduced with permission from: [6] )

Moreover, apart from the polymers in the 6 groups there are polymers quite similar to group 6 polymers, but without electrolyte retaining sidechains. In such polymers, the bulk polymer just comprises conjugated polymer and mobile dopants. One such material is PEDOT:Tos. Tosylate is the monomer of PSS. While in PEDOT:PSS the dopant PSS is immobile, tosylate in PEDOT:Tos can move between the polymer matrix and the environment. Details on the processes occurring in PEDOT:Tos during electrochemical doping can be found in publication 4 . 


\subsection{Hydrogels}

\subsubsection{Fundamentals of Volume Changes in Hydrogels}

Hydrogels are a class of polymeric materials forming three dimensional networks that can contain over $99 \%$ water ${ }^{[10,11]}$.

They are however neither completely solid nor liquid thus exhibiting unique properties that would not be found in either class of materials [11]. To exhibit such properties, hydrogels must meet two functional premises described by the Flory-Rehner theory. The Flory-Rehner theory describes the swelling equilibrium of hydrogels, i.e., the swelling capability, as a sum of a mixing and an elastic component ${ }^{[11]^{*}}$.

$$
\Delta G_{\text {total }}=\Delta G_{\text {mixing }}+\Delta G_{\text {elastic }}
$$

The mixing component $\Delta \mathrm{G}_{\text {mixing }}$ depends on the compatibility between the polymer and the surrounding fluid which is commonly boiled down into a so-called polymer-solvent-interaction parameter $\chi$. This parameter is influenced by many factors such as intermolecular forces like van der Waals interactions, hydrogen bonding, hydrophobic interactions, and electrostatic interactions as well as by temperature and polymer concentration ${ }^{[11]}$. Conversely, the water uptake, i.e., mixing, can be facilitated when polymers exhibit functional groups alongside the polymer backbone. Typical hydrophilic functional groups in hydrogels are -OH, $\mathrm{CONH},-\mathrm{CONH}_{2}$, and $-\mathrm{SO}_{3}{ }^{[12]}$.

The elastic component $\Delta \mathrm{G}_{\text {elastic }}$ describes interactions in the polymer networks. On the one hand, such interactions are necessary to prevent the polymer matrix from dissolving ${ }^{[11]}$. On the other hand, they limit the expansion. Here the space between the crosslinking sites is the defining factor, i.e., the molecular weight of the polymer chains and the molecular weight between the crosslinking sites largely affect the elastic contributions ${ }^{[11,13]}$.

The elastic properties are also influenced by chain relaxation processes and globule-to-coil transitions ${ }^{[11]}$. The latter are described more in detail in the volume change section (3.4) ${ }^{[11]}$.

For the swelling equilibrium of hydrogels, the forces described by the mixing and the elastic components are opposing each other (see Figure $3 \mathrm{a \& b}$ ). Hereby the mixing forces are evoking swelling, while the elastic

\footnotetext{
* In general, for Gibbs free energy: $\Delta \mathrm{G}<0 \rightarrow$ spontaneous reaction

$\Delta \mathrm{G}>0 \rightarrow$ energy needs to be added for the reaction to occur
} 
forces are hampering the swelling. Consequently, the equilibrium swelling occurs when $\left|\Delta \mathrm{G}_{\text {mixing }}\right|=\left|\Delta \mathrm{G}_{\text {elastic }}\right|$ while the swelling is increasing when $\left|\Delta \mathrm{G}_{\text {mixing }}\right|>\left|\Delta \mathrm{G}_{\text {elastic }}\right|$.

a)

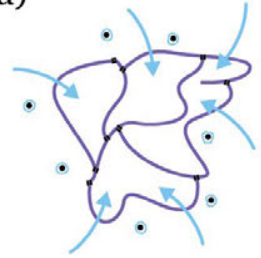

b)

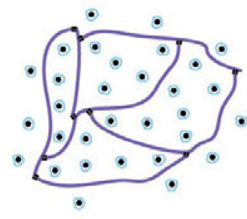

c)

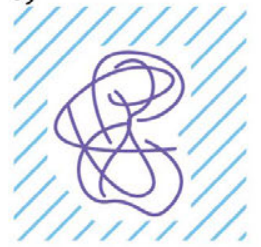

d)

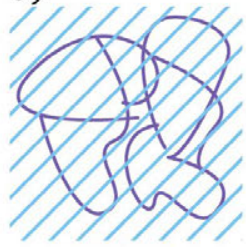

Figure 3 Depiction of mechanisms during the water uptake of hydrogels a) and $b$ ) the limiting effect of crosslinking sites onto the expansion of hydrogels and c) hydrogel before swelling and d) swollen hydrogel (blue = water, purple $=$ polymer chains)

The dynamics of swelling of a hydrogel in a liquid medium vary depending on the characteristics of the mixing and elastic behavior. In the case of Fickian dynamics, i.e., diffusion controlled, the diffusion processes are slower than the chain relaxation processes, and the diffusion of the swelling agent determines the change in degree of swelling [11]. In the case of non-Fickian dynamics, the swelling is relaxation controlled, because the relaxation of the chains is slower than the diffusion of the swelling agent [11].

Since diffusive actions of the swelling agent through the polymer matrix is the main driving force, the volume change in hydrogels is rather slow [11]. In fact, the time of swelling was found to be inversely proportional to the square root of the gel dimensions ${ }^{[14]}$. That means the larger the gel, the longer it takes until it is entirely swollen. The duration for swelling can be in the range of hours ${ }^{[15]}$. However, the speed of swelling is much faster for thin gels, e.g., $1 \mathrm{~s}$ for gels thinner than $10 \mu \mathrm{m}{ }^{[14]}$. The speed of volume change can also be enhanced by introduction of porosity into the hydrogel matrix ${ }^{[11]}$.

The chemical structure of some hydrogels also enables stimuli responsive swelling. Such triggers could be changes in $\mathrm{pH}$, ionic strength, or temperature. More details regarding the stimuli responsive hydrogels can be found in 3.4.1 Volume Changes in Stimuli Responsive Hydrogels.

There are many naturally occurring hydrogel materials like alginate and agarose, that are polysaccharides, or gelatin (denatured collagen), that are protein based [16]. Many of the naturally occurring hydrogel materials have been used by mankind for a long time and even today, natural hydrogels are the most widely used ones ${ }^{[16]}$. In the case of naturally occurring hydrogels, the gelation is often related to entanglement or self- 
assembly of the polymer chains [17]. These processes are driven by noncovalent interactions like hydrogen bonds or hydrophobic interactions [17]. For example, gelatin, when cooled below $36{ }^{\circ} \mathrm{C}$ undergoes a coil to helix conformation resulting in the gelled state ${ }^{[18]}$. Similarly, Agarose self assembles into gel-forming helical structures when cooled down ${ }^{[19]}$. In the case of alginate, another known example of naturally occurring hydrogels, chelation of divalent cations such as $\mathrm{Ca}^{2+}$ governs the gelation [17].

Starting from the middle of the last century also new artificial hydrogel materials such as poly(vinyl alcohol) or poly(ethylene glycol) (PEG) were synthesized [3]. Major advantage of artificial hydrogel materials over naturally occurring ones is, that they can be easily mass produced at constant qualities ${ }^{[16]}$. Not least, concomitant with the bottom-up nature of a synthesis, the properties can be specifically tailored with large freedom [16].

\subsubsection{Applications of Hydrogels}

The unique properties of hydrogels, such as their combination of liquid and solid properties, their ability to uptake large amounts of liquids as well as the accompanying volume changes make them attractive materials for a wide range of applications. Hydrogels can be found in everyday products like processed food, cosmetics and pharmaceuticals [11].

In biotechnology hydrogels can be used as large three-dimensional matrix to store proteins, e.g., enzymes for biosensors [11]. Here the enzymes are immobilized in the polymer matrix while the vast amounts of water in the hydrogel enable unhindered diffusion of the ligands and substrate [11].

The ability to contain molecules in the matrix, their biocompatibility and trigger responsiveness are also properties that make hydrogels attractive for drug release applications ${ }^{[11]}$.

Furthermore, as hydrogels resemble living tissues in many aspects, they are attractive materials for biomedical applications in proximity to tissues ${ }^{[20]}$.

One very commercially successful example of hydrogels used in biomedical applications are soft contact lenses ${ }^{[21]}$. Here the major advantage of hydrogels over hard contact lenses are the wetting properties and the mechanical properties, i.e., softness ${ }^{[21]}$. In addition, the large water content of hydrogels enables the transport of oxygen to the cornea tissue ${ }^{[21]}$. The properties of hydrogels can also be particularly useful for wound dressings. Here the ability of hydrogels to control moisturization and to 
allow gas exchange can enhance the healing process [21]. In addition, stimuli responsive hydrogels can respond to changes in temperature and $\mathrm{pH}$ and then actively balance temperature or release drugs [20].

The similarity of hydrogel properties to living tissues is also one of the reasons why hydrogels find application in cell culture [22] and tissue engineering applications [23]. While the adhesion of cells to hydrogels is generally rather low, the adhesion can be tuned by the introduction of functional groups such as $-\left(\mathrm{CH}_{3}\right)_{2} \mathrm{~N},-\mathrm{SO}_{3} \mathrm{H}$ or $-\mathrm{COOH}{ }^{\text {[24]. }}$.

Because the stiffness of the matrix plays a major role for the cell growth, the settability of the stiffness of the hydrogels by the preparation is another factor that makes hydrogels of interest for cell and tissue applications ${ }^{[25]}$.

The properties of hydrogels make them also interesting materials for implant applications. On the one hand, the similar mechanical properties reduce frictional irritation of the surrounding tissue [24]. On the other hand, the adhesion of immunce cells to hydrogels is low [24].

Not least, stimuli responsive hydrogels can be applied in stimuli responsive volume change applications, as detailed in 3.4.1 Volume Changes in Stimuli Responsive Hydrogels. 


\subsection{Conjugated Polymers with Thiophene Backbone and Glycol Side Chains: p(gXTX)s}

One advantage of (conjugated) polymers is that they can be optimized for the desired applications in many aspects via chemical design. Working points for properties optimization are first and foremost, choosing an appropriate conjugated backbone, with corresponding dopants, but also sidechains or other additives.

Ethylene glycol (EG) is featuring many desirable properties making it attractive as additive or for side chain modification.

General properties that make EG an attractive customization are that it is non-toxic, non-inflammatory and reduces bio film formation ${ }^{[26]}$. In addition, EG sidechains improve solubility of the modified polymer and therefore processability ${ }^{[27]}$.

Not least as an additive to PEDOT:PSS formulations, EG is known to enhance conductivity ${ }^{[28]}$.

Ethylene glycol has also been explored as sidechains of polythiophenes uncovering fascinating properties and applications described below. Owing to an increased number of variations, such ethylene glycol substituted polythiophenes are lately referred to as $\mathrm{p}$ (gXTX) polymers but have been referred to differently before in other works, e.g., as p(gT2) ${ }^{[27]}$. In $\mathrm{p}(\mathrm{gXTX})$, the $\mathrm{gX}$ represents the number of EG repeat units in the side chain, while the TX represents the number of thiophene units. For example, p(g3T2) comprises building blocks of 2 thiophenes with side chains of 3 EG repeat units each, while $\mathrm{p}\left(\mathrm{g}_{1} \mathrm{~T} 2-\mathrm{g}_{5} \mathrm{~T} 2\right)$ comprises two building blocks with sidechains of 1 and 5 EG repeat units respectively on 2 thiophene units each (see Figure 4).

Already in the early 2000s Gallazzi and co-workers explored p(gXTX) like polymers as electronic noses for different organic vapors [29].

However, only lately p(gXTX) polymers considerably gained attraction especially for OMIECs applications. That is because p(gXTX) polymers feature electronic and ionic transport in the polymer bulk even for $\mu \mathrm{m}$ thick films ${ }^{[27]}$. Hereby, the polythiophene backbone enables electronic transport and the EG-sidechains enable ionic transport, while not being susceptible to Red/Ox reactions themselves, i.e., both types of transport are happening in a single molecule (see also section 3.1 Conjugated Polymers -6 classes of OMIECs) ${ }^{[27]}$.

Owing to the properties and molecular features, $\mathrm{p}$ (gXTX) polymers are classified as group 6 OMIECs materials according to a classification scheme recently proposed ${ }^{[6]}$. 


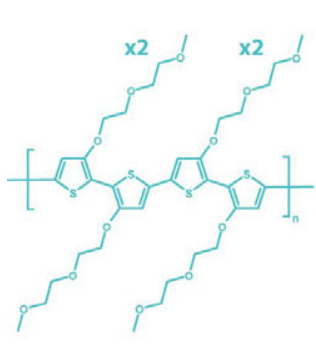

p(g2T2)

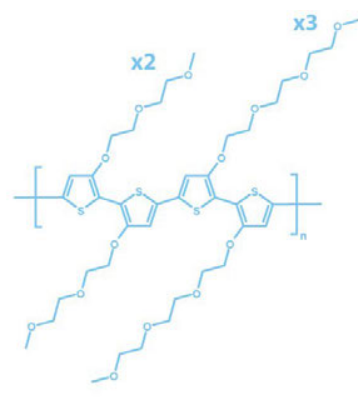

p(g2T2-g3T2)

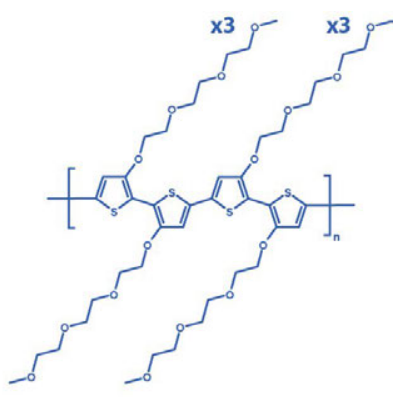

p(g3T2)

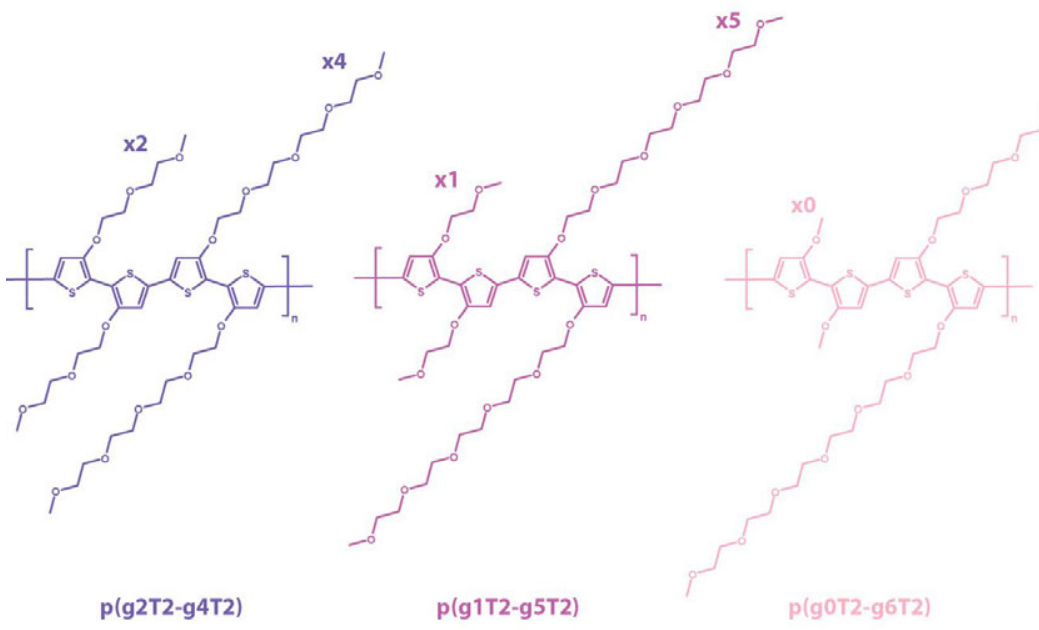

Figure 4 Schematics of different $p(g X T X)$ polymers

The EG sidechains in p(gXTX) not just facilitate ionic transport but also the oxygen atoms in the sidechains lower oxidation potentials of the polymers and increase the charge carrier mobility [30,31]. In addition, EG sidechains have a stabilizing effect on the polymer and improve the thermal stability ${ }^{[31,32]}$.

For ionic transport, the hydrophilic nature of EG sidechains is especially important. When the ions migrate through the polymer bulk during the ionic transport, they drag along water molecules which interact with the EG sidechains ${ }^{[27]}$. Such water uptake also causes a swelling of the material [27].

The volume change capabilities might in fact be the most surprising properties of $\mathrm{p}(\mathrm{gXTX})$ materials, exceeding the volume change capabilities of common conjugated polymers by an order of magnitude. In 
addition, the properties of the polymers in terms of volume change, but also the OMIECs properties, can be further tailored by choosing different side chain lengths ${ }^{[31,33]}$. We found that experimentally, the volume change ability increases with increasing side chain length up to 3 EG repeat units. Likewise, molecular dynamics simulations predicted, that longer side chains induce no further increase in volume change ability [33] (publication 2).

Details on the investigations on the volume change capabilities of $\mathrm{p}(\mathrm{gXTX})$ polymers can be found in publications 1 and 2 and 3.4.2Volume Change in Conjugated Polymers.

Complementing the variations of side chain lengths that we investigated, other research groups explored polymers similar to $\mathrm{p}$ (g2T2) (P3MEET), but with increasing alkyl spacer lengths in the sidechains. It was found that the volume change with ethyl spacer (P3MEEET) is larger than in the case of a methyl spacer or without spacer [34].

One downside of EG-thiophenes is their relative softness. The mechanical properties of EG-thiophenes have been addressed by the introduction of urethane units in the backbone, leading to improved mechanical robustness and smaller volume changes, while the electrochemical properties remained largely unaffected [35].

The swelling behavior of OMIECs materials is also closely linked to the ionic electronic conductivity properties. On the one hand, swelling of the polymers is positively influencing the mixed electronic ionic transport. For example, it was suggested that the performance of organic electrochemical transistors (OECT) is correlating with swelling [36,37]. On the other hand, too much water in the polymer matrix will negatively affect its electronic conductivity and the overall device stability ${ }^{[31,38]}$. Recent studies on OECTs suggest that the ionic electronic transport properties and the swelling of $\mathrm{p}(\mathrm{gXTX})$ materials can be specifically tailored by choosing appropriate EG side chain lengths or combinations of different lengths [31,33]. In fact, $\mathrm{p}(\mathrm{g} 1 \mathrm{~T} 2-\mathrm{g} 5 \mathrm{~T} 2)$ exhibited unprecedented OECT figures of merit $\left[\mu \mathrm{C}^{*}\right]$ of $522 \mathrm{~F} \mathrm{~V}^{-1} \mathrm{~cm}^{-1} \mathrm{~s}^{-1}$ (PEDOT:PSS which is very commonly used for OECTs has a $\mu \mathrm{C}^{*}$ of 47$)^{[28,31]}$.

Apart from the figure of merit, EG functionalized thiophenes feature another major advantage for OECT applications, namely that OECTs made with such materials are off by default and therefore devices with such materials consume less power ${ }^{[39]}$. In the context of OECTS, the subunits of $\mathrm{p}(\mathrm{gXTX})$ polymers have been investigated in combination with other

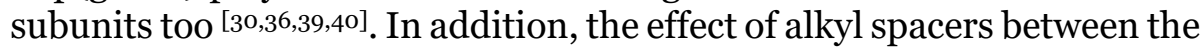
thiophene backbone and the EG sidechains have been investigated, on homo- and co-polymers [34,41]. 


\subsection{Induced Volume Changes in Different Polymer Classes}

Controlled volume changes have a wide range of possible applications, both naturally occurring as well as in technological applications. Important applications of volume changes are actuators (section 4.1 Polymer Actuators) and drug delivery.

\subsubsection{Volume Changes in Stimuli Responsive Hydrogels}

Hydrogels are polymeric materials that can uptake vast amounts of water, so that they comprise to up to $99 \%$ of water (see also section $3.2 \mathrm{Hy}-$ drogels). Depending on structural properties, hydrogels can show a dependency to stimuli including but not limited to changes in temperature and $\mathrm{pH}$. Such properties are based on changes in the hydrophobic/ hydrophilic balances in the polymers [42]. In turn, stimuli responsiveness is facilitated by specific side chains.

\subsubsection{1. pH Sensitive Hydrogels}

Hydrogels can exhibit pH-dependent swelling properties. Such pH-responsive polymers are categorized as anionic or cationic. The former typically feature acidic groups such as carboxylic or sulfonic acids, while the latter feature basic groups like amines ${ }^{[43]}$. Consequently, those polymers can accept or release protons in response to the $\mathrm{pH}$ of the surrounding medium [44]. Changes in protonation lead to changes in ionization, a property closely linked to hydrophilicity, as well as structural changes, e.g., due to electrostatic repulsion, respectively the absence thereof [43,44]. Electrostatic repulsive forces in turn cause osmotic swelling forces, i.e., hydrogel volume changes [43].

Anionic hydrogels exhibit a confined morphology below the threshold $\mathrm{pH}$ and are swollen and expanded above it (basic conditions). Cationic hydrogels exhibit the opposite behavior ${ }^{[43,45]}$. The transition point can be adjusted by the composition of the functional groups of the polymer [44].

\subsubsection{Temperature Sensitive Hydrogels}

Thermoresponsive polymers can be categorized in ones with lower critical solution temperature (LCST) and upper critical solution temperature (UCST) polymers ${ }^{[46]}$. LCST-type polymers are soluble below the critical temperature and insoluble above it, while for UCST-type polymers it is the opposite, i.e., those are soluble above certain temperature [47]. In 
water, hydrogen bonding between water and functional groups are dominating below the threshold temperature of LCST-type polymers [47]. Above LCST hydrogen bonding is diminished and intra- and intermolecular interactions are dominating, causing a change in solubility and morphology $[46,47]$. The change in morphology manifests itself by a literal coil to globule transition (Figure 5) ${ }^{[47]}$.
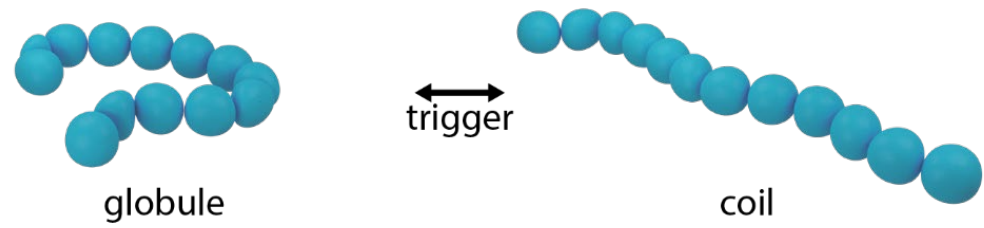

Figure 5 Depiction of a coil-to-globule transition of polymers following triggers such as changes in temperature [42]

However, the transition temperature is not a fixed temperature as such but also strongly dependent to the concentration of the polymer [47]. Hereby, the transition temperature is the lowest at a specific concentration and increasing both at larger and smaller concentrations ${ }^{[46]}$.

Already 1967 poly(N-isopropylacrylamide) (PNIPAAm) was the first polymer to be reported as thermoresponsive and subsequently sparked research interest in such materials and their applications [47]. The properties of PNIPAAm happen to be particularly interesting for many life science applications too, as under physiological conditions, the transition temperature is close to the body temperature ${ }^{[48]}$.

Polyethylene glycol shows thermoresponsive behavior too [47]. Hereby the amphiphilic balance enables the thermoresponsive behavior [47].

\subsubsection{Temperature Sensitive Hydrogels with Ethylene Glycol Side Chains}

Another interesting group of polymers exhibiting thermoresponsive behavior are polymers of the poly(oligo ethylene glycol acrylate)s (poly(OEGA)s) and poly(oligo ethylene glycol meth-acrylate)s (poly(OEGMA)s) families. Similar to the p(gXTX) family, the poly(OEGMA) family combines a hydrophobic polymer backbone with oligo-ethylene glycol sidechains. The solution properties of poly(OEGMA)s are determined by the balance between the hydrophilic (from the ethylene glycol sidechains) and the hydrophobic forces (from the backbone) in the polymer structure ${ }^{[42]}$. Consequently, depending on the ethylene glycol side chain lengths, poly(OEGMA)s can be insoluble in water in the case of short side chains $(<2$ units), readily soluble $(>10$ units) or thermoresponsive (2-10 units) ${ }^{[15]}$. In the thermoresponsive 
window poly(OEGMA)s exhibit a LCST behavior [15]. The thermoresponsive threshold is hereby increasing with the number of sidechain units and can be precisely tailored by combinations of sidechains of different lengths ${ }^{[15]}$. However, the transition temperature is not just affected by the side chain lengths, but also by the overall polymer chain length and the hydrophobicity of the backbones, e.g., when methacrylate is substituted with acrylate ${ }^{[42]}$. Furthermore, also the environment, like the salt in the electrolyte and the concentration thereof, has an impact on the transition effect [49].

Polymers of the poly(OEGMA) family can feature swelling ratios of at least 3 -fold ${ }^{[15]}$. The response times, especially for the swelling are very large, though. It can take thousands of minutes to reach full swelling ${ }^{[15]}$.

\subsubsection{Volume Change in Conjugated Polymers}

Due to the easy interconnection with existing common infrastructure, electrical volume control is of particular interest. Electrical stimuli can induce volume changes in polymers, both as a response to electric fields stimuli, e.g., in dielectric elastomers, which require very large potentials ( $\sim \mathrm{kV}$ range), or through intrinsic electrochemical changes following electrochemical stimuli like in conjugated polymers.

Volume changes in conjugated polymers found wide research attention, among other reasons due to the ease of stimulation by relatively small potentials. Various conjugated polymers such as polythiophenes, PEDOT, polyaniline and polypyrrole (PPy) have been investigated (see table 1). With about 40\% recoverable volume change, polypyrrole is commonly considered as the one exhibiting the largest volume changes among the common conjugated polymers, which typically exhibit volume changes in the single digit percentage range.

However, we recently found that $\mathrm{p}(\mathrm{g} 3 \mathrm{~T} 2)$ can exhibit recoverable volume changes of up to $1400 \%$ (at $+0.5 \mathrm{~V}$ ) and up to $12000 \%$ (at $+0.8 \mathrm{~V}$ ) nonrecoverable with respect to the pristine state. Furthermore p(g3T2) was found to exhibit a reversible volume change of about $300 \%$ for hundreds of cycles (See also 3.3 Conjugated Polymers with Thiophene Backbone and Glycol Side Chains: p(gXTX)s) [33,50].

When the oxidation level of a conjugated polymer changes, it causes changes in carbon-carbon bond lengths, angles between units and interactions between polymer chains and solvent, as well as between polymer chains [51]. Most importantly though, dopants (ionic species) and accompanying solvent are taken in or expelled to maintain charge neutrality (see also section 3.1 Conjugated Polymers) [51]. 
Materials

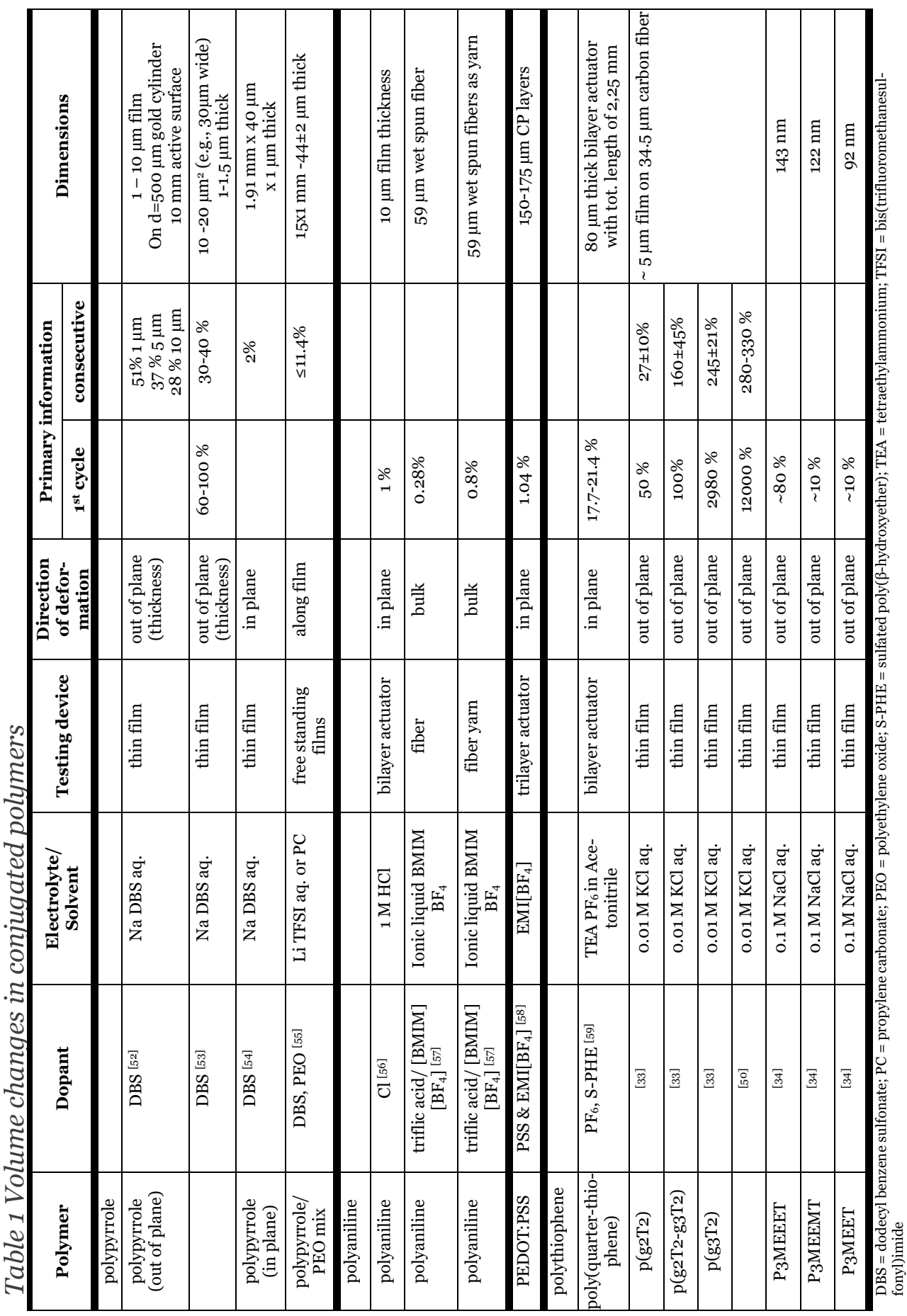


For example, in the case of PPy, there are two cases of electrochemically induced volume change mechanisms (see Figure 6).

In the first case there are only mobile dopants (ionic species) in the system. Therefore, when PPy is oxidized, i.e., electrons are taken from the polymer and positive charges are exhibited on the backbone, mobile anionic dopants enter the polymer matrix to balance the charges [51,60]. Since the oxidation happens for all the polymer chains both at the surface and in the bulk, dopants diffuse also into the bulk of the polymer matrix. This in turn also causes conformational changes to be able to accommodate the dopants and accompanying solvent [61]. The solvent is entering the polymer matrix, on the one hand, as hydration shell of the dopants, on the other hand, due to osmotic pressure caused by the altered charge situation and the dopant movement ${ }^{[60]}$. The uptake of solvent is a major cause of volume change ${ }^{[51]}$.

In the second case apart from PPy the polymer matrix contains immobile large negatively charged dopants ${ }^{[51]}$. Hence the coherencies invert and to balance the charges of the immobile dopant, cationic mobile dopants enter the polymer matrix when PPy is reduced [51]. For the respective cases, when the potentials are reversed the effects are reversed too, i.e., dopants and solvent get expelled and the volume decreases.

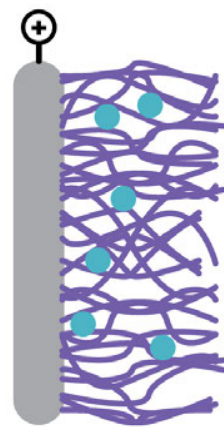

expanded state

(oxidized)

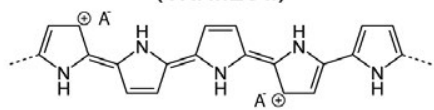

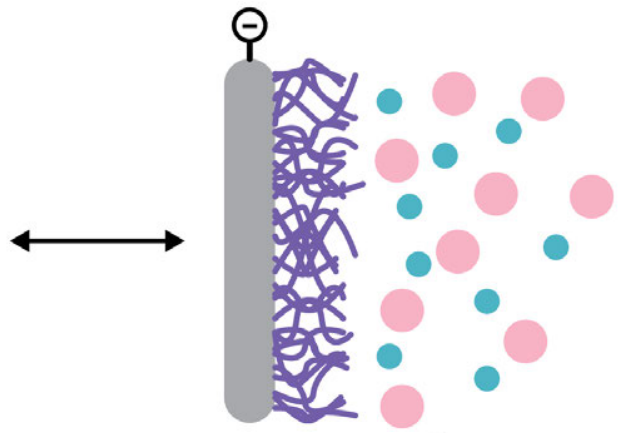

contracted state (reduced)

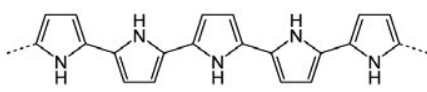

Figure 6 Movement of mobile dopants in polypyrrole following oxidation (left) and reduction (right) (adapted from: [51])

On the level of individual polymer chains a globule-to-coil transition happens (see Figure 5). Here with increasing oxidation of the polymer chain the polymer-dopant (counter ions) and polymer-solvent interactions increasingly dominate ${ }^{[60]}$. Consequently, the polymer chain morphology changes from an initially globule-like state to an elongated state 
with an individual electrochemical double layer (Similar to the observations that occurred in the computational studies in publication 1) ${ }^{[60]}$.

Since the volume changes are directly linked to the number of dopants moved, which in turn is linked to the induced charges, the volume change can be precisely controlled by electrochemistry ${ }^{[60]}$. However, the direct link to the number of dopants moved also implies that the charges that are necessary to drive the actuators scale with the size of the actuators, which limits the actuator size ${ }^{[51]}$.

The connection between the dopant movement, the electrolyte and the volume change also explains why the volume change is susceptible to the ionic strength, the size of the dopants and the electrolyte ${ }^{[62]}$. For PPy for example it was reported that volume changes increased with increasing dimensions of $\mathrm{Li}\left(\mathrm{C}_{\mathrm{n}} \mathrm{F}_{2 \mathrm{n}+1} \mathrm{SO}_{2}\right)_{2} \mathrm{~N}$ in propylene carbonate solution [63]. Then again in aqueous electrolytes sodium dodecylbenzenesulfonate $(\mathrm{Na}$ DBS) is the dopant most commonly used to achieve large volume changes in PPy.

For the polymers of the p(gXTX) family the dopant-electrolyte movement is a major driving force too. In addition, like for poly(OEGMA)s, in $\mathrm{p}$ (gXTX) polymers, there is a the stark contrast of the hydrophobic, conducting, backbone and the hydrophilic side chains.

With quartz crystal microbalance with dissipation (QCM-D) measurements it was found that the viscoelasticity increases when the polymer is oxidized and the volume of the polymer increases, implying a transition to a gel-like state.

In the computational studies, it was shown that the water-sidechain interaction increases significantly with increased oxidation level, while the water-backbone interaction shows only relatively negligible increase. Interestingly, the computational studies unveiled that while the water-polymer interactions increased in expanded state, the $\pi$ - $\pi$-stacking interaction of the polymer backbones with each other remained unaffected. This enables charge transport for the reverse reaction (reduction) even from utmost expanded state. Furthermore, the computational studies unveiled that the individual polymer chains also undergo a globular to coil transition.

Due to the solid-gel transition and the structural similarities between $\mathrm{p}(\mathrm{gXTX})$ and poly(OEGMA)s, it does not come as a surprise that the volume change ability is varying with the EG side chain lengths [33] (publication 2). Such a modulation has also been observed for hydrogels of the poly(OEGMA) family that also have EG side chains but show a temperature dependent switching (see also 3.4.1.3). 



\section{Applications}

\subsection{Polymer Actuators}

Devices that convert different forms of energy into mechanical form are called actuators ${ }^{[64]}$. Actuators are everywhere around us and even in our bodies. In fact, scientists found inspiration in and aspiration from many actuating mechanisms in nature. One such example are our muscles. The properties and capabilities of our muscles are a reference point in many aspects, that want to be matched by soft actuators like those made of conducting polymers. Actuators can be found in plants too. For instance, the stomata or pulvinus (at the root of leaves) are undergoing volume changes governed by water uptake and release to react to environmental conditions ${ }^{[65,66]}$. Such actuators both in design as well as in functionality can be good models for scientists too. After all, water uptake is a main driving force in volume changes in both (responsive) hydrogels and conjugated polymers.

While there are many machines that are more powerful than human muscles, they are usually bulky and made of rigid materials. However, hard materials are not always desirable for actuators, e.g., in robotics where robots work together with humans or for exoskeletons where artificial actuators interface the human body directly. Also, the ability to create and control smallest actuators can be desirable for many applications, for instance in artificial hands or microfluidics.

Hydrogels and conjugated polymer-based actuators have the potential to address many requirements that common machinery falls short with.

\subsubsection{Actuator Applications}

\subsubsection{Soft Robotics}

Robotics is a key application for actuators and the importance of these applications is further rising with the increasing automation [67]. Soft actuators can complement modern robotics in many aspects, as hard grippers are struggling to grasp soft, easy to damage objects ${ }^{[67]}$. In fact, soft robotics are key for compatibility with anthropocentric environments, for complementing humans in collaborative work conditions or for specific applications like tele-operation with smart gloves or prosthetic limbs [67]. First and foremost, softness as such, is important for robotic grabbing tools ${ }^{[68]}$. Another important feature for grabbing tools is feedback. Sensory feedback is vital to distinguish how hard to grasp an object, 
as it provides feedback to distinguish, e.g., a smooth and heavy object from a rough light one but also how sensitive the object is ${ }^{[69]}$. For prosthetic limbs feedback is essential since we often actually do not pay undivided attention to the grasping task in commonly everyday situations but rely on sensory feedback. Such sensory feedback can be provided by conjugated polymers ${ }^{[69]}$. Conjugated polymers, the same that are used for actuation, can simultaneously serve as sensing device, e.g. for temperature or mechanical conditions ${ }^{[70]}$. Based on conjugated polymers different robotic designs have been explored, both for soft robotic grippers but also for walking robots ${ }^{[71,72]}$. However, many of the presented devices are small, suggesting limitations like the energy consumption [51].

\subsubsection{Different Actuator Architectures}

Specific designs of actuators can overcome weaknesses of individual building blocks, to enhance the strengths and tailor the actuator properties to the specific desired applications.

\subsection{2-3 Layer Actuators}

Bilayer actuators are a well-known concept that can be found in bimetal actuators but also in nature, for example in Venus flytraps ${ }^{[66]}$. The concept of bilayer actuators is exploiting differences in the expansion coefficients of the materials that are involved [68]. If one material expands following a stimulus, like heat or potential, the actuator will bend in the direction of the not-stimuli responsive material, thus amplifying the movement, just like in a lever (Figure 7 a) [68]. The concept can be improved by having different shapes of the bilayer actuators, allowing rotary motion (Figure $7 \mathrm{c}$ ) and elongation ${ }^{[68]}$. Another way to enhance the actuation properties are tri-layer actuators that have a coating of active material on two sides that can be stimulated selectively, thereby allowing bending movements in two directions (Figure $7 \mathrm{~b}$ ) [73].

a)

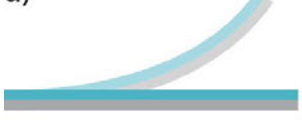

b)

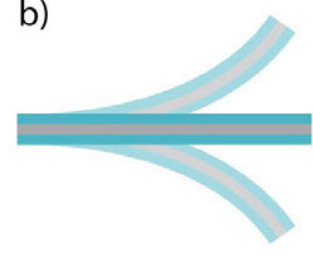

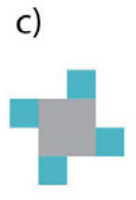

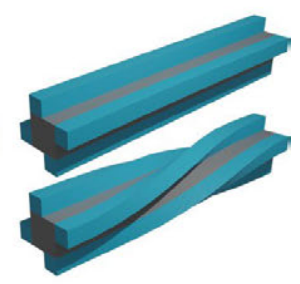

Figure 7 Illustrations of different actuator designs with active layers (turquoise) on top of a passive substrate (gray). a) two-layer actuator design b) three-layer actuator design c) example of an actuator with complex design and actuation (derived from ${ }^{[65]}$ ). 
However, there are downsides to the concept too.

Conjugated polymers, that are widely used for soft actuators based on bi/tri-layer designs, require dopants to move freely between the polymer matrix and the surroundings. The dopants need to be present in the environment of the actuator. The most straightforward approach to achieve that is to operate such actuators in electrolyte, which strongly limits the potential applications [51]. To overcome those limitations, the actuator structure either needs to be sealed with the electrolyte or the electrolyte needs to be replaced altogether, for example with ionic liquids [51]. Such ionic liquids can be contained in a gel matrix in proximity to the active polymers ${ }^{[51]}$. Bi-/tri-layer actuators have also been explored to run just with the humidity of the environment. However changes in humidity itself also cause an actuation [72].

The very fundamental properties enabling these actuators are also impairing the concept. Since the expansion only happens in one of the materials, there are tensions between the materials which cause them to delaminate ${ }^{[51]}$.

Another issue is that the conductivity of conjugated polymers optimized for volume change applications might not be as high as conductivities reported for conductivity optimized polymers [51]. Hereby for volume change applications, the minimum necessary interactions to keep the polymer matrix together are desired, while for good charge transport, high structural order, i.e., crystallinity, with strong $\pi-\pi$-interactions are most favorable ${ }^{[30]}$. Given the required compromises in terms of conductivity, often supporting electrodes are needed to prevent potential drops along the actuators. Such potential drops might hamper the propagation of the stimulus which would consequently lead to an underwhelming actuation ${ }^{[51]}$. Unfortunately, such support electrodes might not be that flexible as they often are thin metal layers, thus compromising the idea of soft actuators.

\subsection{Textile Actuators}

In terms of softness, textile actuators are particularly interesting. These actuators are perhaps the most natural approach for actuators interfacing humans, such as exoskeletons or active compression stockings [74]. Due to the complex structural nature of textiles, textile actuators unlock additional degrees of freedom for optimizing the actuation. On the one hand, yarns, the building blocks of the textiles, can have different structures that can enhance certain desired properties ${ }^{[68]}$. On the other hand, the structure that the yarn has in the fabric allows the tuning of the actuation ${ }^{[68]}$. For example, when the fibers are woven in a $T$ mesh like 
structure, the output force of the fabric can be enhanced while when the same fibers are woven in an $\mathrm{S}$ shaped fashion, the strain can be enhanced (Figure 8) [74]. Parallel yarns in fabrics can be considered as parallel actuators, where the force output scales with the number of yarn threads as well as fibers the yarns consist of ${ }^{[68]}$. In addition, conceptually similar to solutions for advanced actuations in bilayer actuators, combinations of actuating with non-actuating yarns can guide the actuation ${ }^{[68]}$.

a)

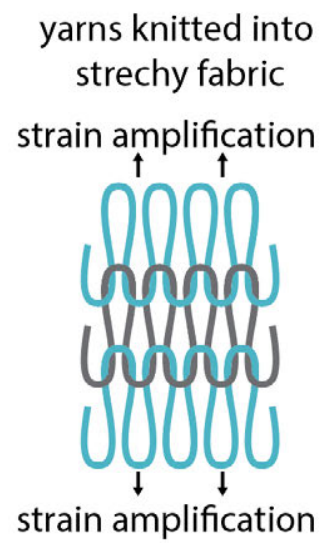

b) yarns assembled in
parralel using weaving

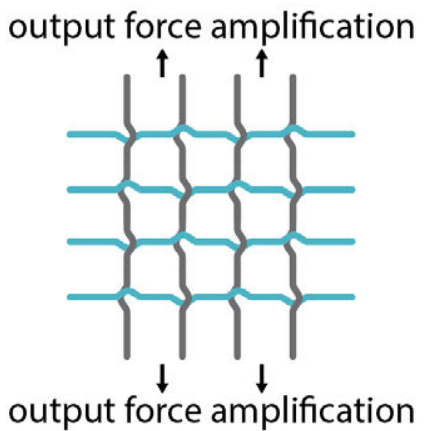

Figure 8 Influence of the weaving pattern on the performance output of actuating fabrics (derived from [74])

The previously mentioned complexity of fabric actuators is held at bay by the well-established mass production technologies of yarns. On the contrary, the established mass production processes can enable large scale production with good repeatability at low costs ${ }^{[68]}$. In fact, the preparation of active actuator yarns might be the most difficult part in the development of such actuators. Conducting polymers for example, which are attractive due to the ease of control by electrochemical signals, are often of insufficiently low molecular weight to generate fibers from them and their mechanical properties are also not adequate for use in textiles ${ }^{[68]}$. More specifically, an increased order in a material (crystallinity), leads to better conductivity, but also larger stiffness [75]. Therefore, often regular yarns, like cotton, are coated with conducting polymers [68]. Conducting polymer coating on supporting yarns can be achieved by dipping the fibers in oxidant and then polymerizing from a monomer bath or by vapor phase polymerization ${ }^{[68]}$.

While conducting polymer-based textile actuators overcome certain disadvantages of $\mathrm{CP}$ actuators, others persist. For actuation conducting polymer actuators require exchange of dopants with the surroundings [64]. The strategies to address that are similar to the ones in other actuator 
designs, however the complex nature of textiles makes it more challenging because the embedding or encapsulation would have to be on the yarn scale. Then again, the entire fabric could be encapsulated as well [68]. This is a well-established technique in textile manufacturing, but such an encapsulation would betray the some of the main advantages of textile actuators such as flexibility and sensation ${ }^{[68]}$.

There are also fabric specific challenges such as the response to washing, abrasion and wrinkles [64]. However, studies on PEDOT:PSS dyed silk and PEDOT:PSS in a polyurethane binder, are promising regarding the wash and wear resistance of conducting fabrics [75].

In addition, when the garment is moving during use conductive yarns might get short circuited [64]. Encapsulation and surface treatments might improve these issues too [64]. For instance, silicone coating can improve mechanical properties and prevent short circuiting [64].

Not least, for on body applications, a major pending question is regarding the impact of the potential release of dopants or fragments of novel polymers on the body ${ }^{[75]}$. 


\subsection{Flow Control with Polymer Actuators}

Volume changes are also of interest for flow control applications such as microfluidics or filters.

In microfluidics the controlled retention of the fluid in functional sections or controlled flow into different functional sections enables more complex systems. The need for such complexity is caused e.g. by biomedical applications such as lab-on-a-chip or micro-total-analysis-systems.

Examples of smart separation applications are filters that change their cutoff size and therefore enable controlled fractioning.

For such applications, the specific properties of conducting polymers and stimuli responsive hydrogels such as hydrophobic-hydrophilic switching and volume change are of great interest.

\subsubsection{Microfluidics}

In microfluidics the size of actuators and ease of addressability are crucial. Polymers can be deposited easily and precisely by techniques common in microsystems technology or printing. Hence there are many possible applications of polymer actuators in microfluidics, for instance as pumps but most prominently in valve applications [65]. Hereby, it is of interest to be able to control the valves with specific triggers like changes in temperature, light or electric field and $\mathrm{pH}$ or even changes in enzyme activity due to substrate addition [65]. The latter two might enable a flow control without external control unit [76]. Valves in microfluidics can typically either exploit volume changes or hydrophobic-hydrophilic switching.

Volume changes can be applied to control flow, as bulk volume changes or indirectly through actuators such as bilayer actuators (see 4.1.1.2.1 23 Layer Actuators). Bulk volume changes can happen directly in the channel exposed to the solution, or with soft interlayers separating the actuator from the fluidic channel [77] (See also Figure 9). These approaches have been tested with various designs, materials and triggers, ranging from conjugated polymers, to $\mathrm{pH}$ or temperature responsive hydrogels $[51,78,79]$.

Flow control in microfluidics has also been realized exploiting the larger displacement ability of bi-/tri-layer actuators, for example as hinges moving a plate to close a channel or petal shaped actuators, resembling the principle of heart valves $[51,80]$.

Wettability changes are a handy way for flow control in microfluidics applications too. In such case, the flow of the electrolyte into a specific 
channel is prevented if the wettability is low and can be enabled by specific stimuli which change the wettability.

Many stimuli responsive polymers also exhibit changes in their hydrophilicity during the polymer switching. For conducting polymers, like polypyrrole or poly(3-hexylthiophene), the wettability properties can be switched electrochemically ${ }^{[81,82]}$. Likewise, for poly(N-isopropylacrylamide), the wetting properties change depending on the temperature [83].

Microfluidics are attractive applications for stimuli responsive hydrogels and conjugated polymers, because due to the small size of the actuators in microfluidics typical limitations of the materials are less prominent.

For instance, since the speed of volume change in hydrogels is inversely linked to the hydrogel volume the switching speed in such materials in active microfluidic valves is sufficient (see hydrogels section 3.2). Similarly, the energy consumption of conducting polymers actuators comes less into play for very small actuators like in microfluidics (see 3.4 Induced Volume Changes in Different Polymer Classes) [51].
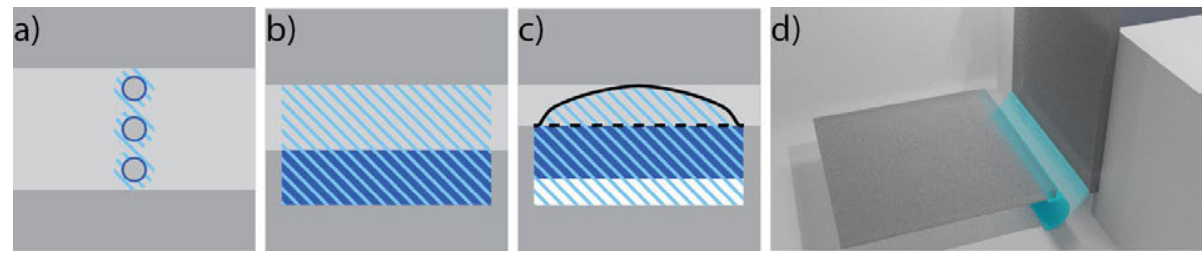

Figure 9 examples of microfluidics valve designs with a) pillar like design b) bulk actuator exposed to microfluidics channel, c) bulk actuator with separation membrane, d) plate-lever microvalve (derived from [51,7] ) (for a-c dark blue indicates contracted state and pale blue lines indicated expanded state)

\subsubsection{Separation Applications}

The underlying phenomena exploited for microfluidics applications have also been applied for bioseparation applications, such as filters.

For example, nanoporous aluminum oxide substrates with polypyrrole as electrochemically volume changing material have been explored to control the flow of fluorescently labelled biotin and bovine serum albu$\min \left[{ }^{84,85]}\right.$. The latter with drug delivery applications in mind ${ }^{[85]}$.

More commonly investigated are membrane filtration setups with conducting polymers. Polypyrrole and polyaniline for example were used on different membrane filter substrates exploiting polymer volume changes resulting from Red/Ox processes to electrochemically vary the cut off size ${ }^{[86-88]}$. 
The specific properties of conducting polymers are also useful for antifouling measures in filter applications. Hereby changes in surface morphology, pore size variations as well as surface charge and wetting properties, all of which in the feature set of conducting polymers, can be exploited ${ }^{[88]}$. 


\section{Methods and Devices}

\subsection{Quartz Crystal Microbalance}

The quartz crystal microbalance (QCM) is a mass sensitive measurement technique based on the piezoelectric effect. The piezoelectric effect was discovered already in $\mathbf{1 8 8 0}$ and describes a material property where a pressure can induce a potential and a potential can induce a deformation [89].

Key property of quartzes is that they feature a resonance frequency at which the amplitude of the oscillation is significantly larger. Among others the resonance frequency is dependent on the quartz geometry. Therefore, quartzes can be specifically designed to exhibit certain resonance frequency. This in turn enables a variety of applications were specific frequencies need to be maintained, e.g., in quartz clocks and radio applications.

For the QCM, potentials are applied to which the quartz responds with a deformation [90]. Again, at certain applied frequency, the resonance frequency, the quartz is oscillating significantly more.

The potential of applying quartzes for detection of mass changes was first described in 1959 by Günter Sauerbrey ${ }^{[89]}$. He first described a relationship between an increasing mass deposition the surface of the quartz and a decreasing resonance frequency of an oscillating quartz, now established as Sauerbrey equation [89]. In vacuum, the Sauerbrey equation in simplified terms looks as follows,:

$$
\Delta m=-(C / n) \Delta f
$$

with mass (m), frequency (f), overtone number (n) (multiples of the fundamental frequency) and $\mathrm{C}$ a constant depending on the quartz properties, e.g., thickness [91]. For a quartz with $5 \mathrm{MHz}$ default resonance frequency, as used in QSense devices, the constant $\mathrm{C}$ is $17.7 \mathrm{ng} \mathrm{cm}^{-2} \mathrm{~Hz}^{-1}$ [92]. Being able to determine the amount of deposited material onto a quartz in vacuum can be very useful to measure film deposition in metal deposition techniques like sputtering.

In the 1980 s new developments also enabled QCM measurements in solution. QCM measurements in solution also allow a combination of QCM with electrochemistry. For measurements in solution, the Sauerbrey equation is applicable too, as long as the films are rigid. However, for viscoelastic films, e.g., hydrogels, more factors must be taken into account. 


\subsubsection{Viscoelasticity}

One way to assess viscoelastic data is to record several overtones (frequency multiples) as well as dissipation. For dissipation measurements the electrical stimulation of the quartz is interrupted, and the decay of the quartz oscillation is monitored. Hereby a rigid film will decay slower than a soft film. The dissipation (D) is inversely proportional to decay time [93]. If the softness of the material at the quartz surface increases, e.g., due to water uptake, then the dissipation increases. Furthermore, the dissipation signals spread. When a deposited material is viscoelastic, then also the frequency shifts of the different overtones vary.

The spread of the dissipation and frequency signal between the different overtones is an easy indication whether the material on the quartz surface is viscoelastic. However, to derive viable information about the viscoelastic properties of the material from the QCM data, viscoelastic modelling is required.

\subsubsection{Limitations of the QCM Technique}

While QCM allows monitoring of changes in mass and viscosity, it is not possible to distinguish the individual contributions of all players in the system. For example, the contribution of the individual dopant species cannot be distinguished as they move in and out of the polymer film following Red/Ox processes. More specifically, two anions in a system, e.g., tosylate and $\mathrm{Cl}^{-}$, cannot be distinguished. The same applies to effects of movement of different cations or water. Therefore, it is beneficial if the system to be measured by QCM is kept as simple as possible.

There are also limits to the film thicknesses that can be measured. For a $5 \mathrm{MHz}$ quartz in aqueous electrolyte, the QCM can probe up to about $250 \mathrm{~nm}$ into the quartz's surroundings, i.e., thicker films might lead to non-viable measurements [90].

The morphology of the deposited films also affects the measurements. This is particularly important for externally applied films. Major inhomogeneities of a film might lead to false results. However, since the QCM is much more sensitive at the center of the quartz surface, the user can carefully assess whether inhomogeneities outside the center of the quartzes surface might be acceptable [94].

For externally applied films it is also important to consider, that every time the quartz is mounted in the setup, a mounting stress is applied which changes the resonance frequency by a couple of $\mathrm{Hz}$. 


\subsection{Image Processing}

\subsubsection{Computational Determination of Polymer Volume on Carbon Fibers}

The volume changes of the polymers were assessed through microscopy. The large number of acquired images for the switching experiments required appropriate solutions to process them.

Image processing is one of the hot topics these days, so naturally there are many ways to extract areas of interest from images. Different approaches have different computational cost.

The character of the acquired images allowed a segmentation of the images based on gray values. This approach is on the one hand computationally frugal, on the other hand easy to grasp.

As a first step the acquired RGB color images were transformed into grayscale values. In grayscale images every pixel has a value between 0 (black) and 1 (white) corresponding to the brightness of the pixel. The shades of gray between black and white are limited by the bit depth of the images. Hereby the higher the bit depth, the more shades can be described ( $2^{\text {(bit depth) }}$ shades).

A grayscale image is essentially a $x-y$-matrix of pixels with gray values. If one now considers a single column in this matrix and plots the gray values one can see that it is possible to distinguish the area of interest from the background by setting a threshold value (see Figure 10). All values below that threshold value can be discarded and all above can be processed further.

a)

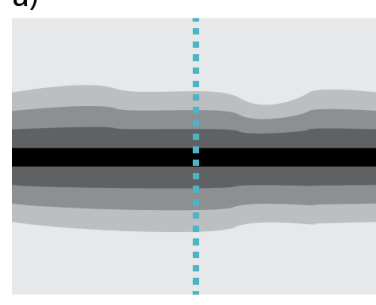

b)

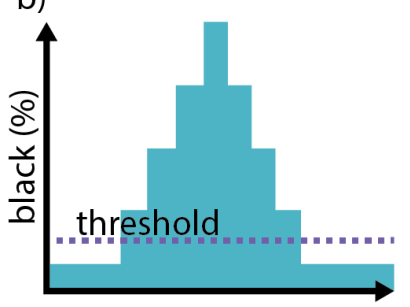

c)

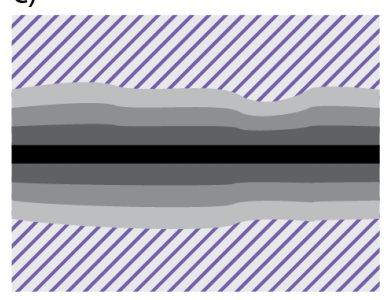

Figure 10 Depiction of the extraction of the polymer coated fiber from a grayscale image. a) representation of a grayscale image, $b$ ) representation of the gray intensities of a cross-section of a) and c) effect of the extraction of the polymer coated fibers from the background based on a gray value threshold

According to the chosen magnification, in micrographs, every pixel represents the average color and intensity of certain area. Hence, if the extracted pixels are counted, the surface they cover can be calculated. 
For a polymer coated carbon fiber, a cylinder shape can be assumed. The volume difference between the total volume of the polymer coated fibers minus the known carbon fiber core equals the volume of the polymer.

The computational analysis of the micrographs was performed with MATLAB.

\subsubsection{Determination of Pore Sizes in Meshes}

The images acquired to quantify the pore size dimensions were also processed with a MATLAB script. Initially the images were straightened and cut. The images were cut to reduce the impact of interferences such as bubbles.

First an image with the pristine state was used to determine the areas with the pores, i.e., areas of interest. After a black and white conversion, the pores were identified with a build in MATLAB function (bwboundaries) and pores that are not fully covered by the selection and such that had stuck bubbles were excluded (Figure $11 \mathrm{a}$ ). The identified areas of interest containing the pores were then dilated (expanded) to also cover the pores in case the microscope selection slightly shifts during the recordings.

The areas of interest identified in the pristine state image were then applied as mask for all the other acquired images of the polymer coated mesh of the same sample.

For every respective area of interest in every image, the open area was determined with a gray value threshold and by counting the pixels meeting the threshold (Figure $11 \mathrm{~b}-\mathrm{d}$ ).

a)

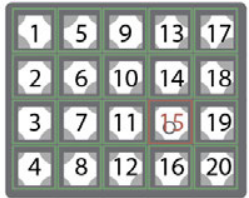

valid

excluded due to bubble b)

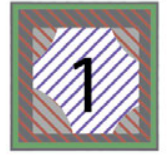

open area closed area

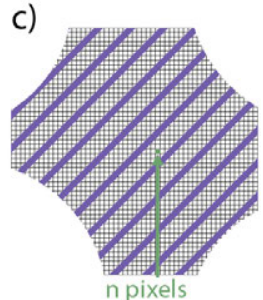

d)

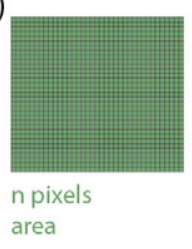

Figure 11 Representation of the steps for processing micrographs of mesh pores, with a) manual identification of valid pores (1-m), b) identification of open area in masked areas (i.e., pore number 1-m) based on gray threshold, c) depiction of the area identified as open area d) representation of all the pixels in the open area 


\subsection{D Printing}

Even though $3 \mathrm{D}$ printers are not a particularly new technology, it was only in the late 2000 s that $3 \mathrm{D}$ printing became affordable and accessible for prosumers and universities.

Most affordable $3 \mathrm{D}$ printers are based on the fused deposition modeling technique. Hereby the polymer is extruded through a nozzle. The polymer is typically fed into the hot extruder where it melts. Since the polymer filament is fed into the extruder, polymer is pushed out of the nozzle. Because the nozzle can move in XY\&Z direction relative to the build platform, layers of polymer could be specifically deposited, creating the $3 \mathrm{D}$ print.

In the present work $3 \mathrm{D}$ prints have been used as a mount for the meshes in the studies on electrochemically controllable meshes for control of dye flow. Detailed descriptions of the setup can be found below in the devices section 5.5. Mesh Setup.

\subsection{Fiber Setup}

\subsubsection{Deposition of Polymers on Carbon Fibers}

Polythiophenes with ethylene glycol sidechains are soluble only in organic solvents, with chloroform as the preferred solvent. Unfortunately, chloroform as a very low boiling point. Therefore, to be able to consistently deposit polymer on carbon fibers it was necessary to reduce the surface of the $\mathrm{p}$ (gXTX) solution during coating of the fibers. This was achieved by having the polymer solution in a capillary (Figure 12). During the coating, the to-be-coated carbon fiber was slowly dragged out of the capillary (after it has been initially placed inside the capillary). Aiming to achieve an as homogenously distributed film around the fiber as possible, the fibers were rotated while they were slowly dragged out of the polymer solution. Due to the fast evaporation of the chloroform the polymer immediately dried on the surface of the fiber once the polymer solution was exposed to ambient conditions where the fiber was dragged out of the capillary.

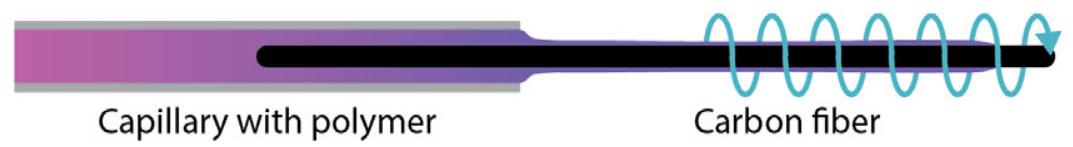

Figure 12 Depiction of the coating setup with a glass capillary containing the polymer solution and a carbon fiber mounted to the shaft of a motor. 


\subsubsection{Micrograph Acquisition of Fibers}

The volume changes of the polymers on the carbon fibers were monitored with a microscope. During the acquisition of the micrographs over up to 12 hours, evaporation of the electrolyte is a major issue. In addition, to be able to compare the images and monitor the changes, the polymer coated fibers should not move. Therefore, the fibers were fixated on a glass slide. After the immobilization of the carbon fibers, a soft hydrophobic barrier of a few millimeter height was placed to form a well to contain the electrolyte $(0.01 \mathrm{M} \mathrm{KCl})$. After the platinum counter electrode and the silver/silver-chloride reference electrode were placed, the well was closed with a second glass slide.

Since the optical effects by the electrolyte and the glass slides vary every time, a non-coated carbon fiber was also mounted in the setup for reference purpose in the computational image processing.

\subsection{Mesh Setup}

For a defined opening and closing of the pores of the meshes a homogenous coating of the mesh is paramount. This was achieved by dipping the meshes $(80 \mu \mathrm{m}$ pore size screen printing metal mesh) in a $15 \mathrm{mg} / \mathrm{ml}$ $\mathrm{p}$ (g3T2) in chloroform solution. To remove excess polymer solution, the meshes were vortexed whilst drying.

a)

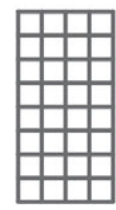

b)

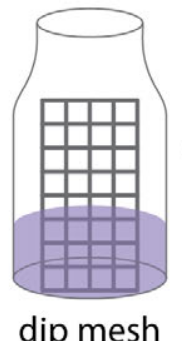

c)

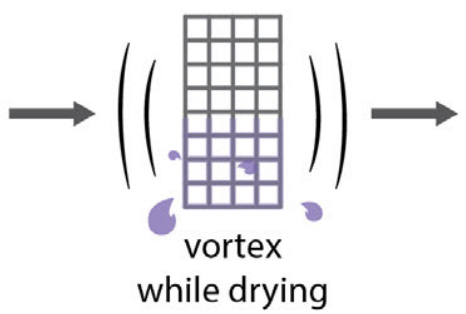

d)

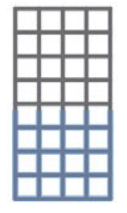

Figure 13 Mesh coating procedure, where the mesh (a) is dipped into the polymer solution (b) and immediately transferred into a vial on top of a vortex mixer, where the excess polymer is removed (c) in order to achieve a homogeneously coated mesh (d)

The meshes were then placed in custom setups for monitoring of the electrochemically controlled pore size variation. The setup comprised several layers, depicted in Figure 14. The mesh is fitted between two layers. For improved view during the investigations a glass is placed between two layers located above the mesh. When all elements are stacked together a chamber forms between the mesh and the glass in which the 
dye can be injected from the side through a notch. The placement of the mesh underneath a glass slide enables monitoring of the pore size variations following electrochemical stimulation. At the same time, since the mesh holder is placed on top of a beaker, the dye passing through the mesh can be monitored with a second camera.

a)

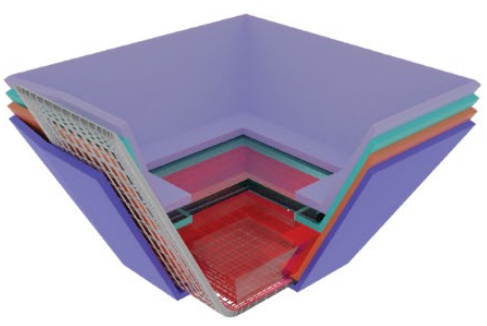

b)

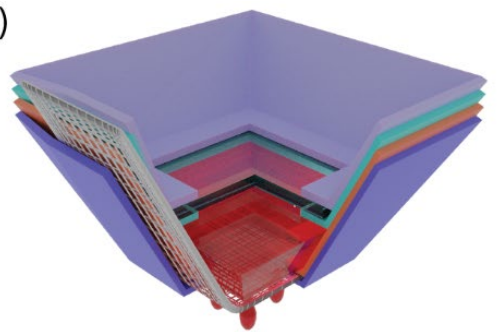

Figure 14 Rendered representation of the holder design for the mesh experiments. The mesh is fitted between the purple and the orange layer. A glass is placed between the turquoise and light purple layer. A larger quantity of concentrated dye is located in the chamber between the mesh and the glass. a) mesh is closed (expanded), no dye is released, b) mesh is open (contracted) dye is released. 



\section{Summary and Outlook}

\subsection{Summary}

Polymers have accompanied mankind for a long time. However, while being a hot topic nowadays, conductivity in polymers was only recognized comparatively recently. The conductivity in conducting polymers is strongly linked to movement of charge carriers, which in turn is linked to volume changes. The typical reversible volume changes of the gold standard conducting polymer material are about $40 \%$. Or that is to say, perhaps was $40 \%$.

During the work of this thesis, it was discovered, that polythiophenes with ethylene glycol sidechains exhibit an electrically controllable reversible volume change much larger than the current reference.

In publication 1 (Reversible Electronic Solid-Gel Switching of a Conjugated Polymer), the volume change capabilities of polythiophenes with ethylene glycol side chains were thoroughly investigated for the first time. The investigated polymer had 3 ethylene glycol (EG) repeat units (g3) and was synthesized from bithiophene subunits (T2). Hence the name $\mathrm{p}(\mathrm{g} 3 \mathrm{~T} 2)$. It was found that following electrochemical stimulation, the polymer can exhibit volume changes of up to $12000 \%$ irreversible and $300 \%$ reversible. The underlying mechanisms of the expansion of the polymers were unraveled by molecular dynamics simulations showing a backbone straightening, and increased water-polymer interaction, while the backbone-backbone interactions remain unaltered.

The remarkable properties of EG-polythiophenes (p(gXTX)s) discovered in the first publication, as well as in independent research on mixed ionic electronic conduction properties, sparked interest in further studies on the impact of the side chain lengths on the volume change capabilities and mixed ionic electronic conductive properties.

In publication 2, (Controlling Electrochemically Induced Volume Changes in Conjugated Polymers by Chemical Design: from Theory to Devices), we observed an increasing trend of the volume change capabilities with increasing sidechain lengths of averages of 2, 2.5 and 3 (p(g2T2), p(g2T2-g3T2), p(g3T2)). However, the investigations showed, that the maximum volume change performance was achieved for $\mathrm{p}$ (g3T2). In addition, molecular dynamics simulations predicted, that $\mathrm{p}$ (g4T2), if synthesized, would not exhibit larger volume changes than $\mathrm{p}(\mathrm{g} 3 \mathrm{~T} 2)$. Focus of the publication was also on the switching stability of the polymers. It was shown, that the after about 100 switching cycles, the 
relative polymer volume changes stabilize and remain stable until at least 300 total switching cycles. Thanks to our collaborators, also the ionic electronic properties of the materials were investigated with organic electrochemical transistors.

Briefly presented as a demonstrator already in the first publication, smart filter applications based on $\mathrm{p}$ (g3T2) were thoroughly explored in publication 3 (An electroactive filter with tuneable porosity). Here, metal meshes ( $80 \mu \mathrm{m}$ pore size) were coated with the polymer by dipping. However, significant improvements of the coating quality were found, when the dipped meshes were shaken in a vortex shaker while drying. Meshes coated as such were found to have similar behavior among the pores in each respective sample as well as good reproducibility. The effect of the coating concentration on the opening/closing-behavior was explored as well. It was found that the pores could be electrochemically opened and closed, with less than $1 \%$ inactive pores. In addition, application of $0.1 \mathrm{~V}$ potential steps enabled specific control of the average pore diameter in about $10 \mu \mathrm{m}$ steps.

Ultimately, it was shown, that it is possible to control flow with meshes prepared in such a way.

The volume changes in $\mathrm{p}(\mathrm{XTX})$ polymers investigated in publications 13 , is driven by charge carriers moving into or out of the polymer matrix following changes in the reduction and oxidation of the polymers. Even though, the volume changes of $\mathrm{p}(\mathrm{gXTX}) \mathrm{s}$ are exceptional, the underlying processes are similar for other conjugated polymers. Hence in publication 4 (Water Intake and Ion Exchange in PEDOT:Tos Film upon Cyclic Voltammetry: Experimental and Molecular Dynamics Investigation), the mass changes in PEDOT:Tos, a well-known conjugated polymer, during cyclic voltammetry were investigated in a complementary study with molecular dynamics ("computational microscopy") and quartz crystal microbalance experiments. It was found that overall, during electrochemical cycling, tosylate gets gradually replaced by chlorine, the water content increases and the total mass decreases. More precisely, during reduction sodium enters the polymer matrix while anionic charge carriers such as tosylate and chlorine leave the polymer matrix. In contrast during oxidation, anionic charge carriers enter the polymer matrix. However, owing to the higher concentration and larger mobility of chlorine, chlorine gradually replaces the tosylate in the PEDOT matrix. 


\subsection{Outlook}

Thorough understanding of the molecular processes in materials of today enables leaps for the materials of tomorrow. The development of conjugated polymers in general is exemplary for that. Likewise, the discoveries made within the context of this thesis might be the foundation to exciting new materials and applications.

Already with the given properties of $\mathrm{p}(\mathrm{gXTX}) \mathrm{s}$, the possibilities for applications and further exploration are manifold.

For example, the ability of the materials to modulate the mechanical properties and conductivity make $\mathrm{p}(\mathrm{gXTX}) \mathrm{s}$ interesting materials worthwhile to explore for cell culture applications, because cells might proliferate differently depending on the mechanical properties of the surroundings or upon electrical stimuli.

The materials' electrically controlled giant volume change and solid-geltransition could be explored for active drug delivery devices that dynamically adjust the released drug amount according to the circumstances. Here, the initially hydrophobic properties and small passive swell in contrast to the active volume change are promising to address burst release and leakage issues, that are a major issue for drug delivery devices.

Then again, to begin with, the volume change capability could be simply explored in common bi-tri-layer actuator designs as well.

Another application of p(gXTX) materials could be antifouling. Not only are ethylene glycol sidechains as such generally considered to be antifouling, but $\mathrm{p}$ (gXTX) also exhibits many typical antifouling properties such as control of hydrophobic-hydrophilic switching, volume change and surface charge all in a single material.

The irreversible volume change and material degradation at excessive potentials observed in publication 1 are promising towards transient electronics, where a p(gXTX) based device is operating within the safe electrochemical window while it is needed and once it is not needed anymore, the degradation could be started by applying excessive potentials.

Despite the exciting properties as is, already now, new chemical designs based on ethylene glycol sidechains like those in p(gXTX)s are explored. For example designs with spacers in the ethylene glycol sidechains, with gXTX units in combination with other monomers or ethylene glycol sidechains on other monomers such as PEDOT were explored $[34,35,39,41,95,96]$. Many of those new chemical designs aim to enhance the OMIECs properties.

However, there are many other challenges that could be addressed by further chemical design. 
Such tweaks could be aiming to enhance the stability of the material, e.g., through the addition of functional groups at the end of the sidechains that would enable crosslinking or thiols at the end of the backbones to enable chemisorption to gold surfaces. An enhanced stability could be of interest for biosensor applications, where $\mathrm{p}(\mathrm{gXTX})$ could serve as conductive matrix or for charge storage applications to enhance the cycling stability. Crosslinkable side groups could also enable binding of functional peptides, which would be beneficial for cell culture applications.

Certainly, chemical designs on the side chains could be explored to further enhance the volume change capability, for example ethyl spacers in a p(g3T2) could be one such modification worth trying [34]. Chemical joints from Calixarenes to direct volume change could be also a worthwhile path to explore with $\mathrm{p}\left(\mathrm{g}_{3} \mathrm{~T} 2\right)^{[97]}$.

The variety and diversity of possibilities for applications and further exploration of just $\mathrm{p}(\mathrm{gXTX}) \mathrm{s}$ highlight the potential of future research in the field of conjugated polymers, where the publications that are part of this thesis are merely a tiny building block. One to hopefully build on. 


\section{Literature}

[1] S. C. Rasmussen, Chempluschem 2o2o, 85, 1412.

[2] Clarivate-Analytics, "Web of Science," can be found under www.webofknowledge.com, 2021.

[3] N. Chirani, L. Yahia, L. Gritsch, F. L. Motta, S. Chirani, S. Faré, J. Biomed. Sci. 2015, 04, 1.

[4] PlasticsEurope, Plastics - the Facts 2020, 2020.

[5] S. C. Rasmussen, Ambix 2018, 65, 356.

[6] B. D. Paulsen, K. Tybrandt, E. Stavrinidou, J. Rivnay, Nat. Mater. 2020, 19, 13.

[7] D. Kiefer, A. Giovannitti, H. Sun, T. Biskup, A. Hofmann, M. Koopmans, C. Cendra, S. Weber, L. J. Anton Koster, E. Olsson, J. Rivnay, S. Fabiano, I. McCulloch, C. Müller, ACS Energy Lett. 2018, 3, 278.

[8] A. I. Hofmann, R. Kroon, S. Zokaei, E. Järsvall, C. Malacrida, S. Ludwigs, T. Biskup, C. Müller, Adv. Electron. Mater. 2020, 6, 2000249.

[9] M. Berggren, G. G. Malliaras, Science (80-. ). 2019, 364, 233.

[10] M. C. Koetting, J. T. Peters, S. D. Steichen, N. A. Peppas, Mater. Sci. Eng. R Reports 2015, 93, 1.

[11] G. Gerlach, K. F. Arndt, Hydrogel Sensors and Actuators, Springer-Verlag Berlin Heidelberg, Berlin Heidelberg, 2009.

[12] S. Sharma, A. Parmar, S. K. Mehta, in Drug Target. Stimuli Sensitive Drug Deliv. Syst. (Ed.: A.M. Grumezescu), Elsevier Inc., 2018, pp. 627-672.

[13] N. A. Peppas, P. Bures, W. Leobandung, H. Ichikawa, Eur. J. Pharm. Biopharm. 2000, 50, 27.

[14] M. A. C. Stuart, W. T. S. Huck, J. Genzer, M. Müller, C. Ober, M. Stamm, G. B. Sukhorukov, I. Szleifer, V. V. Tsukruk, M. Urban, F. Winnik, S. Zauscher, I. Luzinov, S. Minko, Nat. Mater. 2010, 9, 101.

[15] J. F. Lutz, J. Polym. Sci. Part A Polym. Chem. 2oo8, 46, 3459.

[16] R. Rodríguez-Rodríguez, H. Espinosa-Andrews, C. VelasquilloMartínez, Z. Y. García-Carvajal, Int. J. Polym. Mater. Polym. Biomater. 2020, 69, 1.

[17] Y. S. Zhang, A. Khademhosseini, Science (8o-. ). 2017, 356, DOI 
10.1126/science.aaf3627.

[18] M. Djabourov, J. Leblond, P. Papon, J. Phys. 1988, 49, 319.

[19] P. Zarrintaj, B. Bakhshandeh, I. Rezaeian, B. Heshmatian, M. R. Ganjali, Sci. Rep. 2017, 7, 17187.

[20] S. Chatterjee, C. P. Hui, Molecules 2019, 24, 2547.

[21] E. Caló, V. V. Khutoryanskiy, Eur. Polym. J. 2015, 65, 252.

[22] S. R. Caliari, J. A. Burdick, Nat. Methods 2016, 13, 405.

[23] S. Mantha, S. Pillai, P. Khayambashi, A. Upadhyay, Y. Zhang, O. Tao, H. M. Pham, S. D. Tran, Materials (Basel). 2o19, 12, DOI 10.3390/ma12203323.

[24] U. S. K. Madduma-Bandarage, S. V. Madihally, J. Appl. Polym. Sci. 2021, 138, 50376.

[25] N. Huebsch, P. R. Arany, A. S. Mao, D. Shvartsman, O. A. Ali, S. A. Bencherif, J. Rivera-Feliciano, D. J. Mooney, Nat. Mater. 2010, 9, 518.

[26] E. M. Moore, J. L. West, Regen. Eng. Transl. Med. 2019, 5, 167.

[27] D. Moia, A. Giovannitti, A. A. Szumska, I. P. Maria, E. Rezasoltani, M. Sachs, M. Schnurr, P. R. F. Barnes, I. McCulloch, J. Nelson, Energy Environ. Sci. 2019, 12, 1349.

[28] S. Inal, G. G. Malliaras, J. Rivnay, Nat. Commun. 2017, 8, 1767.

[29] M. C. Gallazzi, L. Tassoni, C. Bertarelli, G. Pioggia, 2003, 88, 178.

[30] C. B. Nielsen, A. Giovannitti, D.-T. Sbircea, E. Bandiello, M. R. Niazi, D. A. Hanifi, M. Sessolo, A. Amassian, G. G. Malliaras, J. Rivnay, I. McCulloch, J. Am. Chem. Soc. 2016, 138, 10252.

[31] M. Moser, T. C. Hidalgo, J. Surgailis, J. Gladisch, S. Ghosh, R. Sheelamanthula, Q. Thiburce, A. Giovannitti, A. Salleo, N. Gasparini, A. Wadsworth, I. Zozoulenko, M. Berggren, E. Stavrinidou, S. Inal, I. McCulloch, Adv. Mater. 2020, 32, 2002748.

[32] R. Kroon, D. Kiefer, D. Stegerer, L. Yu, M. Sommer, C. Müller, Adv. Mater. 2017, 29, 1700930.

[33] M. Moser, J. Gladisch, S. Ghosh, T. C. Hidalgo, J. F. Ponder Jr., R. Sheelamanthula, Q. Thiburce, N. Gasparini, A. Wadsworth, A. Salleo, S. Inal, M. Berggren, I. Zozoulenko, E. Stavrinidou, I. McCulloch, Adv. Funct. Mater. 2021, n/a, 2100723.

[34] P. Schmode, A. Savva, R. Kahl, D. Ohayon, F. Meichsner, O. Dolynchuk, T. Thurn-Albrecht, S. Inal, M. Thelakkat, ACS Appl. Mater. Interfaces 2020, 12, 13029. 
[35] S. Zokaei, R. Kroon, J. Gladisch, B. D. Paulsen, W. Sohn, A. I. Hofmann, G. Persson, A. Stamm, P. O. Syrén, E. Olsson, J. Rivnay, E. Stavrinidou, A. Lund, C. Müller, Adv. Sci. 2021, 8, 2002778.

[36] A. Giovannitti, D.-T. Sbircea, S. Inal, C. B. Nielsen, E. Bandiello, D. A. Hanifi, M. Sessolo, G. G. Malliaras, I. McCulloch, J. Rivnay, Proc. Natl. Acad. Sci. U. S. A. 2016, 113, 12017.

[37] E. Stavrinidou, P. Leleux, H. Rajaona, D. Khodagholy, J. Rivnay, M. Lindau, S. Sanaur, G. G. Malliaras, Adv. Mater. 2013, 25, 4488.

[38] A. Savva, C. Cendra, A. Giugni, B. Torre, J. Surgailis, D. Ohayon, A. Giovannitti, I. McCulloch, E. Di Fabrizio, A. Salleo, J. Rivnay, I. Sahika, S. Inal, Chem. Mater. 2019, 31, 927.

[39] C. Cendra, A. Giovannitti, A. Savva, V. Venkatraman, I. McCulloch, A. Salleo, S. Inal, J. Rivnay, Adv. Funct. Mater. 2019, 29, 1807034 .

[40] M. Moser, L. R. Savagian, A. Savva, M. Matta, J. F. Ponder, T. C. Hidalgo, D. Ohayon, R. Hallani, M. Reisjalali, A. Troisi, A. Wadsworth, J. R. Reynolds, S. Inal, I. McCulloch, Chem. Mater. 2020, 32, 6618.

[41] I. P. Maria, B. D. Paulsen, A. Savva, D. Ohayon, R. Wu, R. Hallani, A. Basu, W. Du, T. D. Anthopoulos, S. Inal, J. Rivnay, I. McCulloch, A. Giovannitti, Adv. Funct. Mater. 2021, 31, 2008718.

[42] G. Vancoillie, D. Frank, R. Hoogenboom, Prog. Polym. Sci. 2014, 39, 1074 .

[43] F. Ullah, M. B. H. Othman, F. Javed, Z. Ahmad, H. M. Akil, Mater. Sci. Eng. C 2015, 57, 414.

[44] G. Kocak, C. Tuncer, V. Bütün, Polym. Chem. 2017, 8, 144.

[45] K. M. Ruff, S. Roberts, A. Chilkoti, R. V. Pappu, J. Mol. Biol. 2018, $430,4619$.

[46] Q. Zhang, C. Weber, U. S. Schubert, R. Hoogenboom, Mater. Horizons 2017, 4, 109.

[47] D. Roy, W. L. A. Brooks, B. S. Sumerlin, Chem. Soc. Rev. 2013, 42, 7214 .

[48] C. R. Becer, S. Hahn, M. W. M. Fijten, H. M. L. Thijs, R. Hoogenboom, U. S. Schubert, J. Polym. Sci. Part A Polym. Chem. 2008, 46, 7138 .

[49] J. P. Magnusson, A. Khan, G. Pasparakis, A. O. Saeed, W. Wang, C. Alexander, J. Am. Chem. Soc. 2008, 13O, 10852. 
[50] J. Gladisch, E. Stavrinidou, S. Ghosh, A. Giovannitti, M. Moser, I. Zozoulenko, I. McCulloch, M. Berggren, Adv. Sci. 2020, 7, 1901144.

[51] E. Smela, Adv. Mater. 2oo3, 15, 481.

[52] D. Melling, S. Wilson, E. W. H. Jager, Smart Mater. Struct. 2013 , 22, 104021.

[53] E. Smela, N. Gadegaard, Adv. Mater. 1999, 11, 953.

[54] E. Smela, M. Kallenbach, J. Holdenried, $J$. Microelectromechanical Syst. 1999, 8, 373.

[55] R. Khadka, Z. Zondaka, A. Kesküla, M. S. Khorram, T. T. Khanh, T. Tamm, J. Travas-Sejdic, R. Kiefer, J. Appl. Polym. Sci. 2018, $135,46831$.

[56] Q. Pei, O. Inganäs, in Proc.SPIE, SPIE, Albuquerque, 1993, pp. 28-39.

[57] W. Lu, A. G. Fadeev, B. Qi, E. Smela, B. R. Mattes, J. Ding, G. M. Spinks, J. Mazurkiewicz, D. Zhou, G. G. Wallace, D. R. MacFarlane, S. A. Forsyth, M. Forsyth, Science (80-. ). 2002, 297, 983 .

[58] N. Terasawa, K. Asaka, $R S C A d v$. 2018, 8, 33149.

[59] P. A. Anquetil, H. Yu, J. D. Madden, T. M. Swager, I. W. Hunter, Smart Struct. Mater. 2003 Electroact. Polym. Actuators Devices 2003, 5051, 42.

[6o] T. F. Otero, Chem. Rec. 2018, 18, 788.

[61] T. F. Otero, M. Alfaro, V. Martinez, M. A. Perez, J. G. Martinez, Adv. Funct. Mater. 2013, 23, 3929.

[62] M. E. Wechsler, R. E. Stephenson, A. C. Murphy, H. F. Oldenkamp, A. Singh, N. A. Peppas, Biomed. Microdevices 2019, $21,31$.

[63] S. Hara, T. Zama, W. Takashima, K. Kaneto, Polym. J. 2004, 36, 933.

[64] D. Kongahage, J. Foroughi, Fibers 2019, 7, DOI 10.3390/FIB7030021.

[65] L. Ionov, Adv. Funct. Mater. 2013, 23, 4555.

[66] K. Oliver, A. Seddon, R. S. Trask, J. Mater. Sci. 2016, 51, 10663.

[67] J. Shintake, V. Cacucciolo, D. Floreano, H. Shea, Adv. Mater. 2018, 30, 1707035 .

[68] N.-K. Persson, J. G. Martinez, Y. Zhong, A. Maziz, E. W. H. Jager, 
Adv. Mater. Technol. 2018, 3, 1700397.

[69] J. A. George, D. T. Kluger, T. S. Davis, S. M. Wendelken, E. V. Okorokova, Q. He, C. C. Duncan, D. T. Hutchinson, Z. C. Thumser, D. T. Beckler, P. D. Marasco, S. J. Bensmaia, G. A. Clark, Sci. Robot. 2019, 4, eaax2352.

[70] J. G. Martinez, T. F. Otero, Sensors Actuators, B Chem. 2014, 195, 365 .

[71] E. W. H. Jager, O. Inganäs, I. Lundström, Science (8o-. ). 2000, 288, 2335 .

[72] S. Taccola, F. Greco, E. Sinibaldi, A. Mondini, B. Mazzolai, V. Mattoli, Adv. Mater. 2015, 27, 1668.

[73] E. W. H. Jager, N. Masurkar, N. F. Nworah, B. Gaihre, G. Alici, G. M. Spinks, in 2013 Transducers Eurosensors XXVII 17th Int. Conf. Solid-State Sensors, Actuators Microsystems (TRANSDUCERS EUROSENSORS XXVII), 2013, pp. 542-545.

[74] A. Maziz, A. Concas, A. Khaldi, J. Stålhand, N.-K. Persson, E. W. H. Jager, Sci. Adv. 2017,3 , e1600327.

[75] A. Lund, N. M. van der Velden, N.-K. Persson, M. M. Hamedi, C. Müller, Mater. Sci. Eng. R 2018, 126, 1.

[76] D. T. Eddington, R. H. Liu, J. S. Moore, D. J. Beebe, Lab Chip 2001, 1, 96.

[77] Y. Berdichevsky, Y. H. Lo, Mater. Res. Soc. Symp. - Proc. 2003 , 782, 101.

[78] D. J. Beebe, J. S. Moore, J. M. Bauer, Q. Yu, R. H. Liu, C. Devadoss, B.-H. Jo, Nature 2000, 404, 588.

[79] A. D. Jadhav, B. Yan, R.-C. Luo, L. Wei, X. Zhen, C.-H. Chen, P. Shi, Biomicrofluidics 2015 , 9, 034114.

[8o] Y. Fang, X. Tan, Sensors Actuators, A Phys. 2010, 158, 121.

[81] L. Robinson, A. Hentzell, N. D. Robinson, J. Isaksson, M. Berggren, Lab Chip 2oo6, 6, 1277.

[82] S. K. Pramanik, H. Suzuki, ACS Appl. Mater. Interfaces 2o20, 12, 37741.

[83] N. Yu, S. Wang, Y. Liu, P. Xue, P. Ge, J. Nan, S. Ye, W. Liu, J. Zhang, B. Yang, Langmuir 2017, 33, 494.

[84] C. Prönnecke, M. Staude, R. Frank, H.-G. Jahnke, A. A. Robitzki, Nano Lett. 2018, 18, 6375.

[85] G. Jeon, S. Y. Yang, J. Byun, J. K. Kim, Nano Lett. 2011, 11, 1284. 
[86] L. Xu, S. Shahid, A. K. Holda, E. A. C. Emanuelsson, D. A. Patterson, J. Memb. Sci. 2018, 552, 153.

[87] Y. Wu, L. Nolan, S. Coyle, K. T. Lau, G. G. Wallace, D. Diamond, in 2007 29th Annu. Int. Conf. IEEE Eng. Med. Biol. Soc., 2007 , pp. 4090-4091.

[88] X. Tan, C. Hu, Z. Zhu, H. Liu, J. Qu, Adv. Funct. Mater. 2019, 29, 1903081.

[89] K. A. Marx, Biomacromolecules 2003, 4, 1099.

[90] D. Johannsmann, The Quartz Crystal Microbalance in Soft Matter Research: Fundamentals and Modeling, Springer, Cham Heidelberg New York Dordrecht, 2015.

[91] M. Rodahl, F. Höök, A. Krozer, P. Brzezinski, B. Kasemo, Rev. Sci. Instrum. 1995, 66, 3924.

[92] F. Höök, B. Kasemo, T. Nylander, C. Fant, K. Sott, H. Elwing, Anal. Chem. 2001, 73, 5796.

[93] F. Höök, M. Rodahl, P. Brzezinski, B. Kasemo, Langmuir 1998, 14, 729 .

[94] X. Huang, Q. Bai, J. Hu, D. Hou, Sensors 2017, 17, 1785.

[95] D. Ohayon, A. Savva, W. Du, B. D. Paulsen, I. Uguz, R. S. Ashraf, J. Rivnay, I. McCulloch, S. Inal, ACS Appl. Mater. Interfaces 2021, 13, 4253.

[96] Y. Chen, S.-C. Luo, Langmuir 2019, 35, 1199.

[97] P. A. Anquetil, H. Yu, J. D. Madden, P. G. Madden, T. M. Swager, I. W. Hunter, in SPIE's 9th Annu. Int. Symp. Smart Struct. Mater., 2002, pp. 424-434. 


\section{Part II: Publications}





\section{Papers}

The papers associated with this thesis have been removed for copyright reasons. For more details about these see:

http://urn.kb.se/resolve?urn=urn:nbn:se:liu:diva-175337 


\section{FACULTY OF SCIENCE AND ENGINEERING}

Linköping Studies in Science and Technology, Dissertation No. 2150, 2021 Department of Science and Technology

Linköping University

SE-581 83 Linköping, Sweden

www.liu.se 